\title{
Study of ZnO-CNT Nanocomposites in High-Pressure Conditions
}

\author{
Laura-Madalina Cursaru ${ }^{1}{ }^{\mathbb{D}}$, Sorina Nicoleta Valsan ${ }^{1}$, Maria-Eliza Puscasu ${ }^{1}$, Ioan Albert Tudor ${ }^{1} \mathbb{1}$, \\ Nicoleta Zarnescu-Ivan ${ }^{1}\left(\mathbb{D}\right.$, Bogdan Stefan Vasile ${ }^{2}\left[\right.$ and Roxana Mioara Piticescu ${ }^{1, *(1)}$
}

1 National R\&D Institute for Non-Ferrous and Rare Metals, INCDMNR-IMNR, 077145 Pantelimon, Romania; mpopescu@imnr.ro (L.-M.C.); svalsan@imnr.ro (S.N.V.); epuscasu@imnr.ro (M.-E.P.); atudor@imnr.ro (I.A.T.); nicoleta_sim@yahoo.com (N.Z.-I.)

2 National Research Center for Micro and Nanomaterials, University POLITEHNICA of Bucharest, 011061 Bucharest, Romania; bogdan.vasile@upb.ro

* Correspondence: roxana.piticescu@imnr.ro; Tel.: +40-0213-522-046

Citation: Cursaru, L.-M.; Valsan, S.N.;

Puscasu, M.-E.; Tudor, I.A.;

Zarnescu-Ivan, N.; Vasile, B.S.;

Piticescu, R.M. Study of ZnO-CNT

Nanocomposites in High-Pressure

Conditions. Materials 2021, 14, 5330.

https://doi.org/10.3390/ma14185330

Academic Editor: Andres Sotelo

Received: 12 August 2021

Accepted: 10 September 2021

Published: 15 September 2021

Publisher's Note: MDPI stays neutral with regard to jurisdictional claims in published maps and institutional affiliations.

Copyright: (C) 2021 by the authors. Licensee MDPI, Basel, Switzerland. This article is an open access article distributed under the terms and conditions of the Creative Commons Attribution (CC BY) license (https:/ / creativecommons.org/licenses/by/ $4.0 /)$.

\begin{abstract}
Recently, carbon nanotubes (CNTs) have been used extensively to develop new materials and devices due to their specific morphology and properties. The reinforcement of different metal oxides such as zinc oxide $(\mathrm{ZnO})$ with $\mathrm{CNT}$ develops advanced multifunctional materials with improved properties. Our aim is to obtain ZnO-CNT nanocomposites by in situ hydrothermal method in high-pressure conditions. Various compositions were tested. The structure and morphology of $\mathrm{ZnO}-\mathrm{CNT}$ nanocomposites were analyzed by Fourier transform infrared spectroscopy (FTIR), differential scanning calorimetry-thermogravimetry (DSC-TG), X-ray diffraction (XRD), scanning electron microscopy (SEM), energy dispersive X-ray spectroscopy (EDX), and transmission electron microscopy (TEM). These analyses showed the formation of complex ZnO-CNT structures. FT-IR spectra suggest possible interactions between CNT and ZnO. DSC-TG analysis also reveals the formation of some physical bonds between $\mathrm{ZnO}$ and $\mathrm{CNT}$, through the appearance of endothermic peaks which could be assigned to the decomposition of functional groups of the CNT chain and breaking of the $\mathrm{ZnO}-\mathrm{CNT}$ bonds. XRD characterization demonstrated the existence of $\mathrm{ZnO}$ nanocrystallites with size around $60 \mathrm{~nm}$. The best ZnO:CNT composition was further selected for preliminary investigations of the potential of these nanocomposite powders to be processed as pastes for extrusion-based 3D printing.
\end{abstract}

Keywords: carbon nanotubes; zinc oxide; in situ hydrothermal synthesis; nanocomposites

\section{Introduction}

Nanostructured composites based on metal oxides such as $\mathrm{TiO}_{2}$ or $\mathrm{ZnO}$ are widely studied due to their properties which recommends them for different applications.

It is well-known that $\mathrm{TiO}_{2}$ nanoparticles have been used as photocatalysts for the decomposition of organic compounds due to their enhanced photocatalytic activity, chemical stability, semiconducting properties, being inexpensive and environmentally friendly material.

On the other hand, $\mathrm{ZnO}$ with excellent electronic properties, large band gap energy in the near-UV region $(3.37 \mathrm{eV})$ similar to $\mathrm{TiO}_{2}$, high chemical resistance, strong oxidation ability, non-toxicity, low cost, and earth abundancy [1-6], exhibits better photocatalytic activity than $\mathrm{TiO} 2$ for the decomposition of organic compounds in several cases $[4,7,8]$, when it is obtained as a nanomaterial with a high BET surface area.

$\mathrm{ZnO}$ can be considered as a proper and cheaper choice to $\mathrm{TiO}_{2}$ for pollutants degradation (wastewater treatment) [9]. One of the main advantages in the usage of zinc oxide nanoparticles in wastewater treatment is the fact that this kind of material is environmentalfriendly. $\mathrm{ZnO}$ has been used for photocatalytic decomposition of residual dyes in the treatment of textile and paper wastewater [4,10-12].

Hexagonal $\mathrm{ZnO}$ (wurtzite) presented in Figure 1 can be constructed by considering two interpenetrating lattices similar to II-VI semiconductors. This explains its high efficiency 
as n-type semiconductor photocatalyst in the UV region [13-16]. Consequently, $\mathrm{ZnO}$ can decompose organic contaminants into $\mathrm{CO}_{2}$ and $\mathrm{H}_{2} \mathrm{O}$ in UV light but not in visible light. Therefore, the main drawback of $\mathrm{ZnO}$ nanoparticles consists in its reduced ability to use solar energy efficiently. Considering that photodegradation properties of zinc oxide nanoparticles under visible light need to be improved, an interesting strategy could be to combine the $\mathrm{ZnO}$ with other semiconductors [17-20]. Hence, different $\mathrm{ZnO}$-based composite materials have been considered to increase the photocatalytic activity in the visible spectrum.

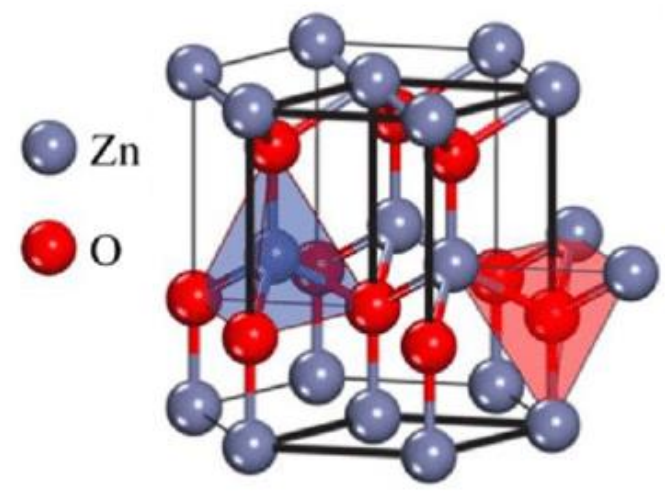

Figure 1. Hexagonal (wurtzite) structure of $\mathrm{ZnO}$ [14].

An intensively studied semiconductor material is represented by carbon nanotubes (CNT). This form of carbon has exceptional structural and electronic properties which can be modified easily by functionalization of the material surface [21]. Carbon nanotubes remain one of the most studied nanomaterials due to its elastic, mechanical, and electrical properties that lead to various applications in energy storage (hydrogen, solar energy), medicine (drug delivery systems), water and wastewater treatment, air pollution control (gas sensor).

Carbon nanotubes can be used in energy storage devices as a result of their high electrical conductivity, high electrolyte accessibility, and stability. CNT presents large specific surface area, fast kinetics, selectivity for aromatic structures, and the capability to remove a great variety of contaminants such as dichlorobenzene, $\mathrm{Ni}(\mathrm{II}), \mathrm{Pb}^{2+}, \mathrm{Cu}^{2+}, \mathrm{Cd}^{2+}$, ethyl benzene, dyes, bacteria, viruses, etc., [22,23].

Carbon nanotubes have also been studied for environmental applications due to their distinctive hollow structure, significant electronic, conductive, and physical properties as well as chemical inertness $[15,16,24]$. CNTs have a mesoporous surface that allows pollutants to be physically adsorbed on $[6,25,26]$.

However, CNT disadvantages represented by its poor dispersion ability and problematic separation process prevent the use of this adsorbent material by itself $[18,27,28]$.

In order to overcome the limitations of the above-mentioned materials, a possible solution can be to obtain a ZnO-CNT-based composite. The photocatalytic activity of zinc oxide combined with the reinforcement and adsorption properties provided by CNT could lead to a material with promising photocatalytic efficiency, surface area and electrical conductivity [29]. Moreover, carbon nanotubes act as a photosensitizer for $\mathrm{ZnO}$ improving its photocatalytic performance in the visible light [30]. So far, numerous studies have reported the improved photocatalytic efficiency of $\mathrm{ZnO}$ in presence of carbon nanotubes [31-33]. The combination of CNT capacitance and metal oxide pseudocapacitive properties can improve the structural and electrochemical features of the materials used in energy storage devices. Thus, $\mathrm{ZnO}-\mathrm{CNT}$ nanocomposites have a tremendous potential in the fabrication of electrochemical capacitors [34]. In different studies, $\mathrm{ZnO}$ nanoparticles successfully bind to the surface of CNTs, as a result of electrons that flow from the conduction band of $\mathrm{ZnO}$ to carbon nanotubes surface $[35,36]$.

ZnO-CNT nanocomposite shows many improved mechanical, electrical, and sensing properties that cannot be attained by CNTs and $\mathrm{ZnO}$ alone. The nanodevices developed 
using ZnO-CNT nanocomposite come with improved performance and numerous applications, such as nanoresonators [37], biosensors with high sensitivity and selectivity [38-42] and super capacitors [43]. The studied nanocomposite opens the door to develop new devices with enhanced properties and thus expanding the applications of $\mathrm{ZnO}$ and CNT in the field of nanotechnology [44].

Various preparation methods [44] have been used in order to improve the tremendous properties of $\mathrm{ZnO}-\mathrm{CNTs}$ nanocomposite. Among these, solution-based methods (such as solvothermal decomposition, hydrothermal process, sol-gel hydrothermal method, microwave assisted synthesis $[6,9,24,45-54]$ ), vacuum-based methods (such as reactive magnetron sputtering, atomic layer deposition, filtered cathodic vacuum arc technique, gasphase deposition, aerosol techniques $[19,31,32,55])$, and mechanical alloying or mechanical mixing method $[44,56]$ are mentioned.

For example, Wang et al. [51] have prepared CNT-ZnO composites (with $20 \%$ and $30 \% \mathrm{ZnO}$, respectively) in solution (chemical method) starting from organic precursors. The final products were thermally treated at $400{ }^{\circ} \mathrm{C}$ for $2 \mathrm{~h}$ to remove the organic part. Dai et al. [48] and Ranjithkumar et al. [53] used chemical reflux method for the synthesis of CNT-ZnO nanocomposites. Azqhandi et al. [24] applied microwave-assisted hydrothermal method to obtain Cd-doped $\mathrm{ZnO} / \mathrm{CNT}$ nanocomposites. In 2009, Yan et al. [9] investigated hydrothermal synthesis of $\mathrm{ZnO}-\mathrm{CNT}$ nanocomposite starting from $\mathrm{ZnO}$ nanoparticles prepared previously and acid-treated multi-walled carbon nanotubes (MWCNT). In 2006, Zhang et al. [55] have grown $\mathrm{ZnO}$ nanowires on modified carbon nanotube arrays by a hydrothermal process. Low amount of acid-treated MWCNT $(<1 \%)$ have also been incorporated in $\mathrm{ZnO}$ by mechanical mixing [56].

The aim of this study is to demonstrate the feasibility of hydrothermal method (a wellknown wet chemical synthesis procedure) to develop new types of $\mathrm{ZnO}-\mathrm{CNT}$ nanocomposite powders in high-pressure conditions for further use in additive manufacturing process (extrusion-based 3D printing) of $\mathrm{ZnO}-\mathrm{CNT} 3 \mathrm{D}$ structures.

To our knowledge, no research data regarding fabrication of $\mathrm{ZnO}-\mathrm{CNT} 3 \mathrm{D}$ structures by additive manufacturing techniques were found. As a novelty, ZnO-CNT nanocomposite powders resulted from hydrothermal synthesis are further used to test their potential to be processed in the form of pastes for extrusion-based 3D printing.

In the present paper, $\mathrm{ZnO}-\mathrm{CNT}$ nanocomposites having different $\mathrm{ZnO}$ : CNT mass ratios are synthesized in situ by hydrothermal process in high pressure conditions, starting from multi-wall carbon nanotubes (MWCNT) functionalized by acid treatment and watersoluble $\mathrm{Zn}$ salt (as ZnO precursor). Zinc oxide is obtained in the presence of MWCNT functionalized with carboxylic groups (MWCNT-COOH), aiming to form a nanocomposite structure with physical bonds between $\mathrm{ZnO}$ and MWCNT-COOH. Both functionalized MWCNT and ZnO-CNT nanocomposite powders were characterized by physical, structural, and thermal methods. The best $\mathrm{ZnO}: \mathrm{CNT}$ composition was selected for preliminary investigations regarding the obtaining of some printable pastes that can be used in additive manufacturing of nanocomposite 3D structures.

\section{Materials and Methods}

MWCNT powder (outer diameter $=10 \mathrm{~nm}$; inner diameter $=4.5 \mathrm{~nm}$; length $=4 \mu \mathrm{m}$ ) was purchased from Sigma-Aldrich, St. Louis, MO, USA; nitric acid p.a., $65 \%$ G.R. $\left(\mathrm{HNO}_{3}\right)$ was purchased from LACH-NER, Brno, Czech Republic; sodium hydroxide, reagent grade, $\geq 98 \%$, was purchased from Lachema, Brno, Czech Republic; sulfuric acid 95-97\%, and zinc nitrate hexahydrate, $\mathrm{Zn}\left(\mathrm{NO}_{3}\right)_{2}{ }^{*} 6 \mathrm{H}_{2} \mathrm{O}$ reagent grade, $98 \%$, were purchased from Merck, Darmstadt, Germany.

\subsection{Functionalization of Multi-Walled Carbon Nanotubes (MWCNT)}

Multi-walled carbon nanotubes were dispersed in a solution of $\mathrm{HNO}_{3}: \mathrm{H}_{2} \mathrm{SO}_{4}=1: 3$ (\%vol) and stirred magnetically or ultrasonicated for $8 \mathrm{~h}$. Thus, obtained solutions were centrifuged several times at $6000 \mathrm{rpm}, 30 \mathrm{~min}$, until pH =4-4.5, using a Rotofix 32A cen- 
trifuge, Hettich Zentrifugen, Tuttlingen, Germany and then the samples were evaporated under reduced pressure in a Heidolph Rotary Evaporator, Laborota 4000, Schwabach, Germany or lyophilized with an Alpha 1-2 LDplus freeze dryer (Martin Christ Gefriertrocknungsanlagen $\mathrm{GmbH}$, Osterode am Harz, Germany). The resulted CNT powders were subjected to spectral, thermal, and morpho-structural characterizations to demonstrate the functionalization of CNT. The experimental working conditions for the functionalization of MWCNT are shown in Table 1.

Table 1. Representative samples of CNT functionalized by acid treatment.

\begin{tabular}{ccc}
\hline Sample Name & \multicolumn{1}{c}{ Composition } & Drying Method \\
\hline CNTFAS-1 & $\mathrm{HNO}_{3} 4 \mathrm{M}: \mathrm{H}_{2} \mathrm{SO}_{4} 10 \mathrm{M}=1: 3$ & rotary evaporation \\
\hline CNTFAS-5 & $\mathrm{HNO}_{3} 2 \mathrm{M}: \mathrm{H}_{2} \mathrm{SO}_{4} 10 \mathrm{M}=1: 3$ & freeze drying \\
\hline CNTFAS-6 & $\mathrm{HNO}_{3} 2 \mathrm{M}: \mathrm{H}_{2} \mathrm{SO}_{4} 5 \mathrm{M}=1: 3$ & freeze drying \\
\hline
\end{tabular}

\subsection{Hydrothermal Synthesis of $\mathrm{ZnO}-\mathrm{CNT}$ Nanocomposites}

Nanocomposite materials based on $\mathrm{ZnO}$ and functionalized CNT were obtained by hydrothermal process, using as precursors $\mathrm{Zn}\left(\mathrm{NO}_{3}\right)_{2} \cdot 6 \mathrm{H}_{2} \mathrm{O}$, functionalized CNT powder, and $\mathrm{NaOH}$ solution $0.5 \mathrm{M}$. CNT powder functionalized as described above (Section 2.1) was dispersed in $\mathrm{NaOH}$ solution $0.5 \mathrm{M}$, brought to $\mathrm{pH}=4-4.5$ and ultra-sounded for $15 \mathrm{~min}$, resulting in a CNT solution. Zinc nitrate hexahydrate was dissolved in water and gradually added, under magnetic stirring, to the CNT solution previously heated to $50^{\circ} \mathrm{C}$. Several types of $\mathrm{ZnO}-\mathrm{CNT}$ nanocomposite powders with different CNT:ZnO weight ratios were prepared (as presented in Table 2).

Table 2. Representative ZnO-CNT nanocomposite powders prepared by hydrothermal synthesis.

\begin{tabular}{cc}
\hline Nanocomposite Sample Code & Composition (Weight Ratio) \\
\hline CNT-ZnO-2 & CNT:ZnO = 1:10 \\
\hline CNT-ZnO-3 & CNT:ZnO = 1:5 \\
\hline CNT-ZnO-4 & CNT:ZnO = 1:4 \\
\hline
\end{tabular}

After precipitation with $\mathrm{NaOH}$ solution $0.5 \mathrm{M}$ at $\mathrm{pH}=9-9.5$, the resulted suspension was poured into the Teflon reaction vessel and introduced in a $1000 \mathrm{~mL}$ autoclave (SAM Romania) for hydrothermal synthesis at $200{ }^{\circ} \mathrm{C}$ and $100 \mathrm{~atm}$. After hydrothermal treatment, nanocomposite powder was filtered and washed with distilled water up to $\mathrm{pH}=7$, then dried in oven at $100{ }^{\circ} \mathrm{C}$. ZnO-CNT nanopowders were further investigated by spectral, thermal, morpho-structural, and physical characterization methods in order to find which $\mathrm{CNT}: \mathrm{ZnO}$ mass ratio is proper for the fabrication of $3 \mathrm{D}$ nanocomposite structures.

\subsection{Spectral, Thermal and Morpho-Structural Characterization of the Prepared Samples}

Fourier Transform Infrared Spectroscopy (FT-IR) analysis was accomplished with an ABB MB 3000 FT-IR spectrometer (ABB Inc., Québec, QC, Canada), using the EasiDiff device (PIKE Technologies, Inc., Madison, WI, USA) for powders measurement. The solid composite sample ( $1 \%$ by weight) is mixed with $\mathrm{KBr}$. For data acquisition, 64 scans were run at a resolution of $4 \mathrm{~cm}^{-1}$ between 550 and $4000 \mathrm{~cm}^{-1}$. All spectra were registered in transmittance mode. Experimental data were processed using the Horizon MB ${ }^{\mathrm{TM}}$ FTIR software version 3.4.0.3 (ABB Inc., Québec, QC, Canada).

Differential scanning calorimetry-thermogravimetry (DSC-TG) analysis was performed using the Setaram Setsys Evolution device (Setaram Instrumentation, Caluire, France), in an inert gas atmosphere. Samples were introduced in alumina crucibles and heated up to $800{ }^{\circ} \mathrm{C}$, with heating rate of $10 \mathrm{~K} / \mathrm{min}$ and cooling rate of $10 \mathrm{~K} / \mathrm{min}$. Experimental data were processed with Calisto software v1.097 (Setaram Instrumentation, Caluire, France). 
X-ray diffraction (XRD) characterization was carried out with a Bruker-AXS D8 ADVANCE diffractometer Bragg-Brentano diffractometer (Bruker AXS GmbH, Karlsruhe, Germany) with radiation source $(\mathrm{Cu})$ and $S O L X$ vertical geometry detector $\theta-\theta$, equipped with BRUKER AXS software. Diffraction spectra were acquired in the angular range $4-74^{\circ}$, continuously, with a step of $0.02^{\circ}$. The phase identification was done with the DIFFRAC.EVA software release 2016 (Bruker AXS GmbH, Karlsruhe, Germany) and the ICDD database PDF $4+2020$.

Morphological characterization was achieved with a scanning electron microscope SEM Quanta 250 (FEI Company, Eindhoven, The Netherlands) in high vacuum (HV), using the secondary and backscattered electron detector (ETD), and the energy-dispersive detector (EDS).

TEM investigations were made using a high-resolution transmission electron microscope Titan THEMIS (Thermo Fisher Scientific, Waltham, MA, USA-Former FEI), operated at $200 \mathrm{kV}$. The selected sample was dispersed into a small amount of distilled water, and ultrasonicated for $5 \mathrm{~min}$. After that $10 \mu \mathrm{L}$ of suspension was placed onto a 400-mesh lacey carbon coated copper grid.

\subsection{Extrusion-Based 3D Printing of ZnO-CNT Nanocomposite Powders}

Preliminary experiments have been performed to prepare proper pastes from $\mathrm{ZnO}$ CNT nanocomposite powders for fabrication of $\mathrm{ZnO}-\mathrm{CNT} 3 \mathrm{D}$ structures by extrusion-based $3 \mathrm{D}$ printing. Selected nanocomposite powders (sample code CNT-ZnO-2) were mixed with different polymeric additives (dispersants, extrusion agents, viscosity agents) using a Thinky-ARE 250 planetary centrifugal mixer (Thinky Coroporation, Tokyo, Japan) to prepare a homogenous and printable paste, with the removal of air bubbles. The container used for mixing and degassing (defoaming) the paste is the $10 \mathrm{~mL}$ cartridge of the 3DBioplotter printer. All the prepared pastes were subjected to 2 min of mixing with a speed of $2000 \mathrm{rpm}$ and $2 \mathrm{~min}$ of defoaming with a speed of $2000 \mathrm{rpm}$. ZnO-CNT 3D structures were obtained by extrusion-based 3D printing method with the 3D-BioPlotter Starter system (EnvisionTEC GmbH, Gladbeck, Germany) by dispensing the paste from the $10 \mathrm{~mL}$ cartridge through a needle tip of $0.4 \mathrm{~mm}$ diameter from a 3-axis system. A printing speed of $8-15 \mathrm{~mm} / \mathrm{s}$ and a pressure range of $2-4$ bars were applied. In order to create the 3 D object, square cuboids with dimensions of $10 \times 10 \times 5 \mathrm{~mm}$ were designed with CAD software (SolidWorks 2019, Dassault systems, Waltham, MA, USA). The inner pattern of the designed sample had a line-based hatch type, with continuous strands and a distance between strands of $1.7 \mathrm{~mm}$. The rotation angle between 2 successive layers was $45^{\circ}$ and $135^{\circ}$, respectively.

\section{Results and Discussion}

\subsection{Hydrothermal Synthesis of ZnO-CNT Nanocomposites}

The hydrothermal method has several advantages over other methods because it does not use organic or organo-metallic precursors that require subsequent heat treatments (calcination, sintering), it is environmentally friendly because it takes place in closed reaction systems and nano-crystalline powders with controlled size and shape are formed directly from the solution [57-59]. It is a relatively cheaper method of synthesis because it requires lower temperatures than other methods $\left(<350{ }^{\circ} \mathrm{C}\right)$.

Unlike Ding et al. [60] who obtained a ternary HA/ZnO/CNT nanocomposite by hydrothermal reaction at $180^{\circ} \mathrm{C}$ for $8 \mathrm{~h}$, this paper proposes the application of an external pressure in hydrothermal synthesis conditions, which should favor the physical interactions between zinc oxide and carboxylic groups on the surface of carbon nanotubes.

In this case, the reaction time is shortened to $2 \mathrm{~h}$ and the energy consumption is reduced because less energy is needed to apply a pressure of $100 \mathrm{~atm}$ into the reaction system than to increase the temperature by a few degrees. According to [61,62] the energy required to increase the temperature by 5 units is the same as that required to increase the pressure by 4000 units. 
By applying an external pressure (argon bubbling above the reaction vessel in which the precursor suspension of $\mathrm{ZnO}-\mathrm{CNT}$ is located), a small compressibility appears in the reaction medium and chemical reactions characterized by a negative $\Delta \mathrm{V}$ value $(\Delta \mathrm{V}$ representing the volume difference between reaction products and reactants) take place.

Due to the applied pressure, solubility of the solvated species increases and the distance between these solvated species decreases, so the chemical reactivity improves.

In addition, dissolution/precipitation reactions take place at the liquid/solid interface until thermodynamic equilibrium is reached.

Under pressure conditions, the mechanism of hydrothermal reactions changes, the reaction rate being determined by diffusive processes.

Chemical reaction for hydrothermal synthesis of $\mathrm{ZnO}$ synthesis in the presence of functionalized CNT and formation of ZnO-CNT nanocomposite can be written as follows:

$$
\begin{array}{r}
\mathrm{Zn}\left(\mathrm{NO}_{3}\right)_{2} \cdot 6 \mathrm{H}_{2} \mathrm{O}+2 \mathrm{NaOH}=\mathrm{Zn}(\mathrm{OH})_{2}+2 \mathrm{NaNO}_{3}+6 \mathrm{H}_{2} \mathrm{O} \\
\mathrm{Zn}(\mathrm{OH})_{2}+\mathrm{MWCNT}-\mathrm{COOH} \stackrel{\text { hydrothermal synthesis }}{\longrightarrow} \mathrm{Zn}-\mathrm{O}-\mathrm{OOC}-\mathrm{MWCNT}+\mathrm{H}_{2} \mathrm{O} \\
\mathrm{Zn}(\mathrm{OH})_{2} \stackrel{\text { precipitation } / \text { re-dissolving }}{\Longleftrightarrow} \mathrm{ZnO}+\mathrm{H}_{2} \mathrm{O}
\end{array}
$$

During hydrothermal synthesis, precipitation/re-dissolving reactions of $\mathrm{ZnO}$ from $\mathrm{Zn}(\mathrm{OH})_{2}$ take place simultaneously with the interactions between $\mathrm{ZnO}$ and functionalized carbon nanotubes (denoted as MWCNT-COOH in Equation (2)). The solvated species in the reaction medium are $\mathrm{Zn}^{2+}$ (which is surrounded by water molecules) and MWCNT-COO ${ }^{-}$. As explained above, the distance between these species decreases at high pressure and physical interactions between hydroxide ions around $\mathrm{Zn}$ and carboxyl groups of carbon nanotubes may occur.

The reactants $\left(\mathrm{Zn}^{2+}, \mathrm{MW}-\mathrm{COOH}, \mathrm{NaOH}\right)$ and the reaction products $\left(\mathrm{ZnO}, \mathrm{NaNO}_{3}\right.$, $\mathrm{ZnO}-\mathrm{CNT}$ ) as well as a proposed reaction mechanism for hydrothermal synthesis of $\mathrm{ZnO}$ CNT nanocomposite structure are depicted in Figure 2.

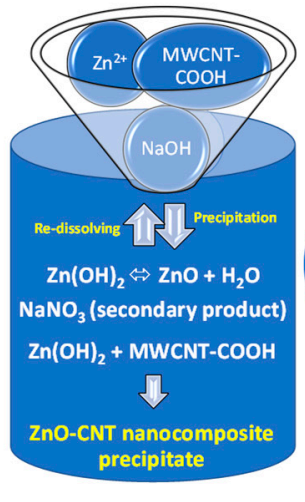

(a)
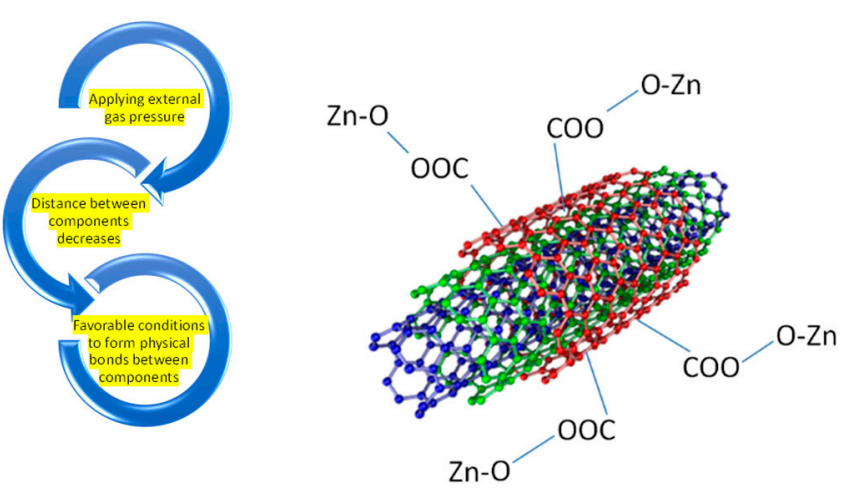

(b)

Figure 2. (a) The formation of the nanocomposite with physical interactions between the two components ( $\mathrm{ZnO}$ and MWCNT-COOH); (b) possible structure of $\mathrm{ZnO}-\mathrm{CNT}$ nanocomposite obtained by hydrothermal synthesis in high pressure conditions.

\subsection{Spectral (FT-IR) Analysis of CNT and $\mathrm{ZnO}-\mathrm{CNT}$ Samples, Respectively}

In order to verify whether the acid treatment of CNT led to the formation of carboxylic groups on the CNT surface, the samples obtained were characterized by FT-IR and DSC-TG. Moreover, the FT-IR analysis may emphasize the formation of ZnO-CNT nanocomposites. FT-IR spectra of the functionalized carbon nanotubes (named CNTFAS-i, as presented in Table 1) are shown in Figure 3. In the case of CNTFAS-1 sample $\left(\mathrm{HNO}_{3}: \mathrm{H}_{2} \mathrm{SO}_{4}=1: 3\right.$ (\%vol) mixture of $4 \mathrm{M} \mathrm{HNO}_{3}-10 \mathrm{M} \mathrm{H}_{2} \mathrm{SO}_{4}$ ), the presence of the following vibration 
bands is observed: the stretching vibration of the hydroxyl group from $\mathrm{COOH}(v \mathrm{O}-\mathrm{H})$ at $3437-3466 \mathrm{~cm}^{-1}[63,64]$; deformation vibration of the OH group at $3096-3059 \mathrm{~cm}^{-1}$; the stretching vibration of the C-H group at 2953-2889 $\mathrm{cm}^{-1}$ [63,64]; vibrations corresponding to carbon nanotube chain at $1614 \mathrm{~cm}^{-1}$ [63], C-C bond at 1323-1284 $\mathrm{cm}^{-1}$ [63], and the stretching vibration of the $\mathrm{C}-\mathrm{O}$ group from $\mathrm{COOH}$ at 1178 and $1070 \mathrm{~cm}^{-1}$ [64]. For all the other investigated samples, dispersion of commercial MWCNT in $\mathrm{HNO}_{3}: \mathrm{H}_{2} \mathrm{SO}_{4}=1: 3$ (\%vol) mixture of $2 \mathrm{M} \mathrm{HNO}_{3}-10 \mathrm{M} \mathrm{H}_{2} \mathrm{SO}_{4}$, (CNTFAS-5) and $\mathrm{HNO}_{3}: \mathrm{H}_{2} \mathrm{SO}_{4}=1: 3$ (\%vol) mixture of $2 \mathrm{M} \mathrm{HNO}_{3}-5 \mathrm{M} \mathrm{H}_{2} \mathrm{SO}_{4}$ (CNTFAS-6), respectively, dried by lyophilization, the FT-IR spectra does not reveal the broad peak assigned to hydroxyl groups in the region 3400-3000 $\mathrm{cm}^{-1}$. Vibration modes related to CNT could be observed in Figure 3b: C-H stretching vibration appears at 2993, $2878 \mathrm{~cm}^{-1}$ (in CNTFAS-5), and $2887 \mathrm{~cm}^{-1}$ (in CNTFAS-6); a small shoulder that could be assigned to CNT chain occurs at $1650 \mathrm{~cm}^{-1}$ (for CNTFAS-5) and $1684 \mathrm{~cm}^{-1}$ for CNTFAS-6. Stretching vibration of C-C bond was detected at $1319 \mathrm{~cm}^{-1}$ (CNTFAS-5), 1321, and $1288 \mathrm{~cm}^{-1}$ (CNTFAS-6). A sharp peak of C-O bond was also found at $1184 \mathrm{~cm}^{-1}$ in the case of CNTFAS-6 sample. Based on these results, it can be considered that $\mathrm{CNT}$ functionalization occurs in the following experimental conditions: dispersion of commercial multi-walled carbon nanotubes (MWCNT) in a mixture of $\mathrm{HNO}_{3}$ $4 \mathrm{M}$ and $\mathrm{H}_{2} \mathrm{SO}_{4} 10 \mathrm{M}$, with $\mathrm{HNO}_{3}: \mathrm{H}_{2} \mathrm{SO}_{4}=1: 3$ (\%vol), followed by centrifugation and evaporation under reduced pressure (CNTFAS-1 sample).

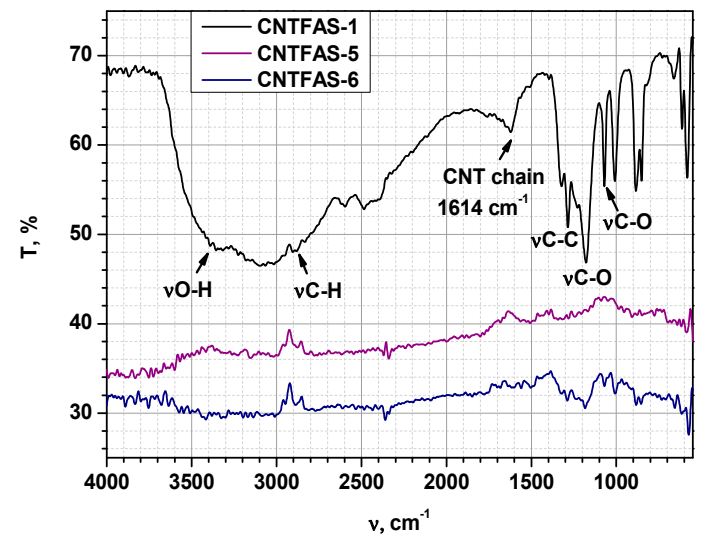

(a)

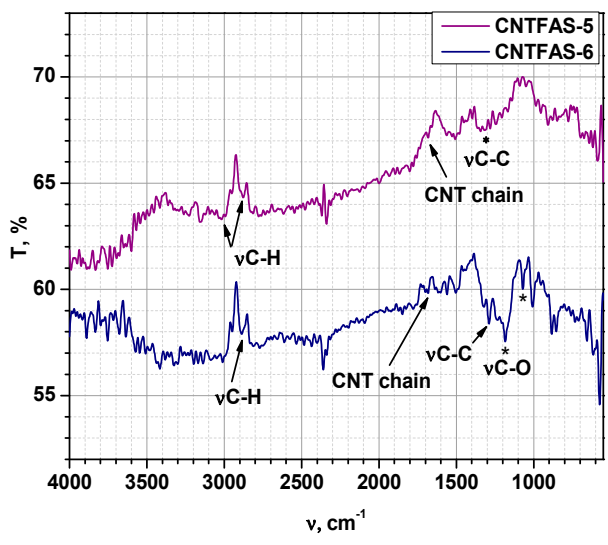

(b)

Figure 3. (a) FT-IR spectra of CNT samples functionalized by acid treatment. Concentration of $\mathrm{HNO}_{3}$ was $4 \mathrm{M}$ in the case of CNTFAS- 1 and respectively $2 \mathrm{M}$ in the case of CNFAS- 5 and CNTFAS- 6 samples. Concentration of $\mathrm{H}_{2} \mathrm{SO}_{4}$ was $10 \mathrm{M}$ for CNTFAS- 1 and CNTFAS- 5 sample, respectively $5 \mathrm{M}$ for CNTFAS-6 sample; (b) detailed FT-IR spectra of CNTFAS-5 and CNTFAS-6 samples.

FT-IR spectra of ZnO-CNT powders described in Table 2 are revealed in Figure 4. A broad peak corresponding to the stretching vibration of the hydroxyl group from $\mathrm{COOH}$ $(v \mathrm{O}-\mathrm{H})$ is observed at $3389-3398 \mathrm{~cm}^{-1}$; vibrations corresponding to the C-H group (around $2900 \mathrm{~cm}^{-1}$ ) and to the carbon nanotube chain (around $1614 \mathrm{~cm}^{-1}$ ), respectively, cannot be observed in the case of nanocomposite powders. These vibrations are probably masked by $\mathrm{ZnO}$ which incorporates the whole CNT chain inside its structure; other typical bands assigned to functionalized CNT (at 1284 and $1323 \mathrm{~cm}^{-1}$, probably associated to the $\mathrm{O}-\mathrm{H}$ bending deformation mode of the $\mathrm{COOH}$ group) $[63,64]$ are shifted to higher wavenumbers (1300 and $1383 \mathrm{~cm}^{-1}$, respectively) in the case of ZnO-CNT nanocomposites. This could be explained by the formation of the structure presented in Figure 2, where some physical bonds between the functional groups of $\mathrm{CNT}$ and zinc oxide are expected. Characteristic stretching vibration of metal-oxygen bond (Zn-O in this case) appears at $592 \mathrm{~cm}^{-1}$ [65]. 


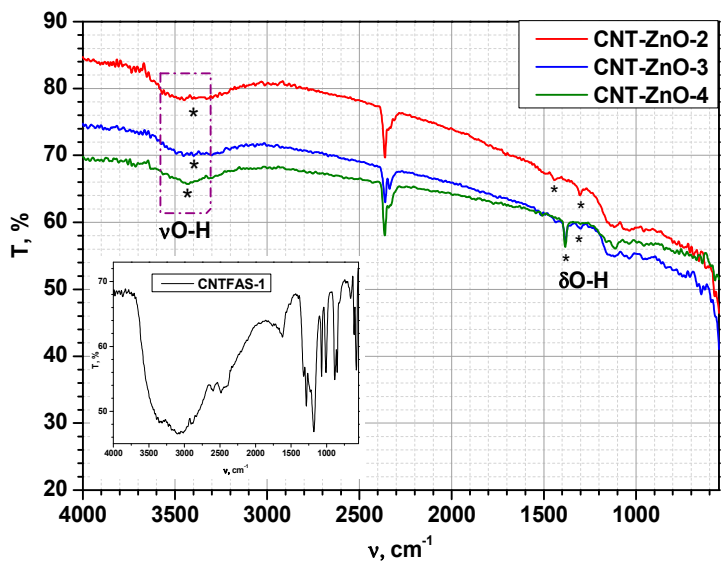

(a)

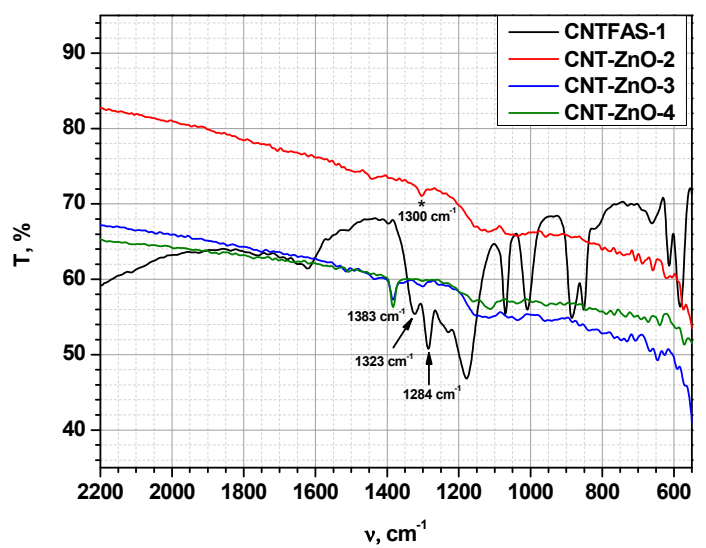

(b)

Figure 4. FTIR spectra of ZnO-CNT samples compared to functionalized CNT (CNTFAS-1) in the range of: (a) $4000-550 \mathrm{~cm}^{-1}$. Inset shows FT-IR spectrum of CNTFAS-1 sample; (b) 2000-550 cm c $^{-1}$ CNT:ZnO weight ratio for CNT-ZnO-2 = 1:10; for $\mathrm{CNT}-\mathrm{ZnO}-3=1: 5$ and respectively for CNT-ZnO-4 = 1:4.

\subsection{Thermal (DSC-TG) Analysis of CNT and $\mathrm{ZnO-CNT} \mathrm{Samples}$}

The results obtained at thermal analysis for all CNT samples treated with acid mixtures of various concentrations are presented in Figure 5 and Table 3. Thermal behavior of ZnOCNT nanocomposites powders and functionalized CNT sample (CNTFAS-1) are presented comparatively in Table 4 and Figure 6.

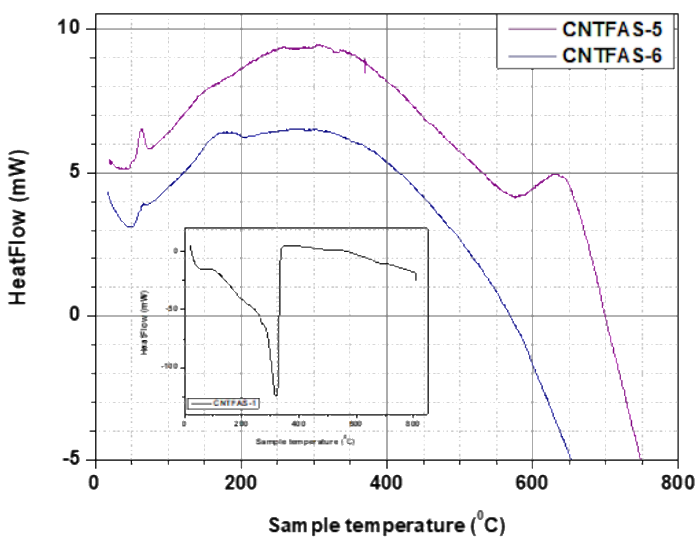

(a)

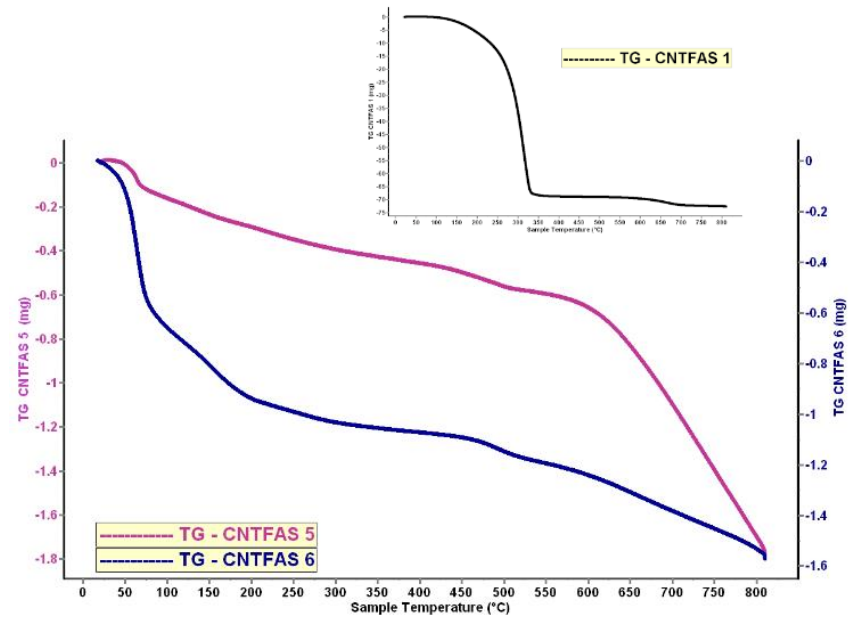

(b)

Figure 5. (a) DSC-TG curves for: CNTFAS-5 and CNTFAS-6 samples versus CNTFAS-1 sample (inset). (b) TG curves for CNTFAS-5 and CNTFAS-6 samples versus CNTFAS-1 sample (inset).

Table 3. Thermal effects and mass loss $(\Delta \mathrm{m})$ in acid-treated CNT powders.

\begin{tabular}{|c|c|c|c|c|c|c|c|}
\hline \multirow{2}{*}{ Sample Name } & \multicolumn{2}{|c|}{$\begin{array}{c}\text { Peak 1 } \\
\text { (Endotherm) }\end{array}$} & \multicolumn{2}{|c|}{$\begin{array}{c}\text { Peak } 2 \\
\text { (Endotherm) }\end{array}$} & \multicolumn{2}{|c|}{$\begin{array}{c}\text { Peak } 3 \\
\text { (Endotherm) }\end{array}$} & \multirow{2}{*}{$\Delta \mathrm{m}$ Total, $\%$} \\
\hline & $\mathrm{T},{ }^{\circ} \mathrm{C}$ & $\Delta \mathrm{H}, \mathrm{J} / \mathrm{g}$ & $\mathrm{T},{ }^{\circ} \mathrm{C}$ & $\Delta \mathrm{H}, \mathrm{J} / \mathrm{g}$ & $\mathrm{T},{ }^{\circ} \mathrm{C}$ & $\Delta \mathrm{H}, \mathrm{J} / \mathrm{g}$ & \\
\hline CNTFAS-1 & & & & & 321.8 & 762.4 & -94.865 \\
\hline CNTFAS-5 & 46.6 & 19.9 & 78.1 & 46.0 & & & -44.211 \\
\hline CNTFAS-6 & 47.5 & 10.9 & 204.3 & 2.9 & & & -17.416 \\
\hline
\end{tabular}


Table 4. Thermal effects and mass loss $(\Delta \mathrm{m})$ in $\mathrm{ZnO}-\mathrm{CNT}$ nanocomposite powders.

\begin{tabular}{|c|c|c|c|c|c|c|c|c|c|c|}
\hline \multirow{2}{*}{ Sample Name } & \multicolumn{2}{|c|}{$\begin{array}{c}\text { Peak 1 } \\
\text { (Endotherm) }\end{array}$} & \multicolumn{2}{|c|}{$\begin{array}{c}\text { Peak } 2 \\
\text { (Endotherm) }\end{array}$} & \multicolumn{2}{|c|}{$\begin{array}{c}\text { Peak } 3 \\
\text { (Endotherm) }\end{array}$} & \multicolumn{2}{|c|}{$\begin{array}{c}\text { Peak4 } \\
\text { (Endotherm) }\end{array}$} & \multirow{2}{*}{$\Delta \mathrm{m}$ Total, $\%$} & \multirow{2}{*}{$\begin{array}{c}\% \text { CNT } \\
\text { (Theoretic) }\end{array}$} \\
\hline & $\mathrm{T},{ }^{\circ} \mathrm{C}$ & $\Delta \mathrm{H}, \mathrm{J} / \mathrm{g}$ & $\mathrm{T},{ }^{\circ} \mathrm{C}$ & $\Delta \mathrm{H}, \mathrm{J} / \mathrm{g}$ & $\mathrm{T},{ }^{\circ} \mathrm{C}$ & $\Delta \mathrm{H}, \mathrm{J} / \mathrm{g}$ & $\mathrm{T},{ }^{\circ} \mathrm{C}$ & $\Delta \mathrm{H}, \mathrm{J} / \mathrm{g}$ & & \\
\hline CNT-ZnO-2 & 63.2 & 20.4 & 233.7 & 75.4 & - & - & 631.7 & 26.3 & 9.7 & 9.1 \\
\hline CNT-ZnO-3 & 46.5 & 15.6 & $\begin{array}{l}196.5 \\
231.6\end{array}$ & $\begin{array}{c}91.0 \\
5.1\end{array}$ & 290.9 & 29.4 & - & - & 17.6 & 16.7 \\
\hline CNT-ZnO-4 & 55.2 & 18.6 & 231.5 & 65.3 & 326.3 & 2.1 & - & - & 18.4 & 20 \\
\hline
\end{tabular}

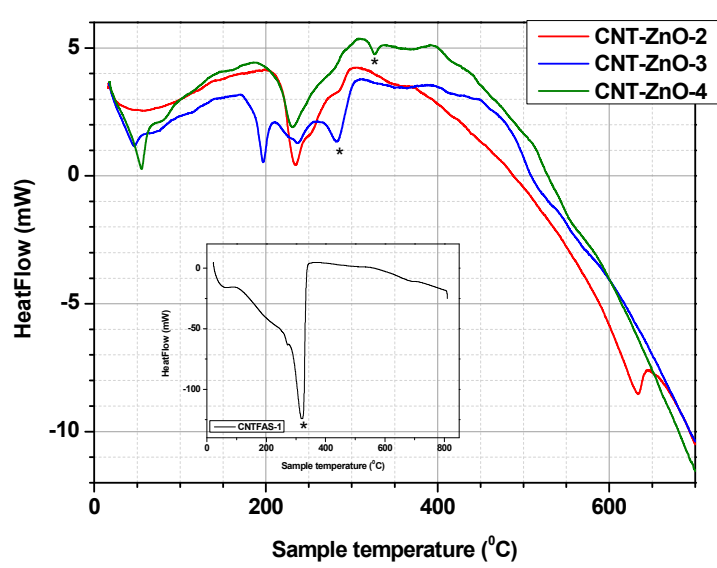

(a)

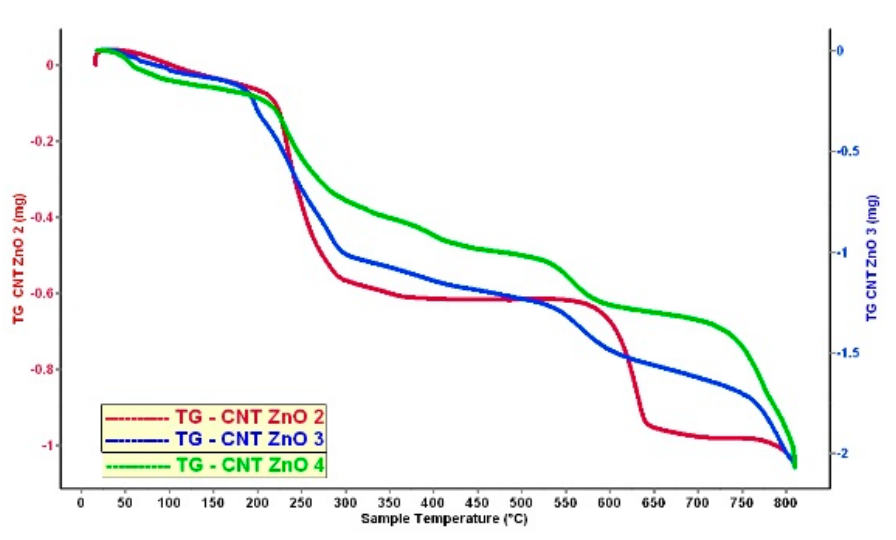

(b)

Figure 6. (a) DSC-TG curves for: CNT-ZnO samples versus CNTFAS-1 sample (acid mixture 4 M:10 M). CNT:ZnO weight ratio for CNT-ZnO-2 = 1:10; for CNT-ZnO-3 = 1:5 and respectively for CNT-ZnO-4 = 1:4; Inset shows DSC curve of CNTFAS-1 sample (acid mixture 4 M:10 M); (b) TG curves forCNT-ZnO-2,CNT-ZnO-3 and CNTZnO-4 samples.

DSC-TG curve of CNTFAS-1 sample (shown as a detail in Figure 5), presents a large endothermic peak at $320-322{ }^{\circ} \mathrm{C}$, which could demonstrate CNT functionalization by the presence of carboxyl groups on its surface [66]. As it could be seen in Figure 3, no endothermic peaks corresponding to decomposition of potential carboxylic groups created on the surface of carbon nanotubes are present in CNTFAS- 5 and CNTFAS- 6 samples, confirming the hypothesis derived from FT-IR results, namely that CNTFAS- 1 is the only sample functionalized with carboxylic groups.

In the case of nanocomposite powders, the first endothermic peak is located at $46-63{ }^{\circ} \mathrm{C}$ (as presented in Table 4) and could be due to the water evaporation from the surface. It can be observed that ZnO-CNT-based nanocomposite materials are thermally stable up to around $230^{\circ} \mathrm{C}$. A correlation between the total mass loss of nanocomposite samples and CNT content is observed (Table 4), demonstrating the presence of functionalized carbon nanotubes in the nanocomposites structure. The endothermic peaks that appear at $233.7^{\circ} \mathrm{C}(\mathrm{CNT}-\mathrm{ZnO}-2), 196.5^{\circ} \mathrm{C} / 231.6^{\circ} \mathrm{C}$ (CNT-ZnO-3), and $231.5^{\circ} \mathrm{C}(\mathrm{CNT}-\mathrm{ZnO}-4)$ are probably explained by the breaking of the physical bonds which may appear between carboxylic groups of functionalized MWCNT and $\mathrm{ZnO}$ (as shown in Figure 2).

The decomposition of CNT functional groups into $\mathrm{CO}_{2}$ can be observed at $290.9{ }^{\circ} \mathrm{C}$ in the case of CNT-ZnO-3 (containing $16.7 \%$ functionalized CNT) and $326.3^{\circ} \mathrm{C}$ for CNT-ZnO-4 (containing 20\% functionalized CNT), similar to CNTFAS-1 sample (which decomposes at $321.8^{\circ} \mathrm{C}$, as shown in the detail of Figure 6). This could be due to an excess of CNT in the nanocomposite structure.

In the case of CNT-ZnO-2 sample with a content of $9.1 \%$ functionalized CNT, no endothermic peak which could be owed to the decomposition of functional groups in the CNT chain was observed. The endothermic peak that appears at $631.7^{\circ} \mathrm{C}$ could be explained by the oxidation of MWCNT to $\mathrm{CO}_{2}[51,67]$. This could be explained by a 
better interaction of CNT with $\mathrm{ZnO}$ during hydrothermal synthesis. Therefore, we can consider that CNT-ZnO-2 sample has an optimal composition for the formation of the nanocomposite with physical interactions between the two components.

\subsection{Morphological Characterization of Functionalised CNT Sample and $\mathrm{ZnO}-\mathrm{CNT}$ Nanocomposites by Scanning Electron Microscopy (SEM)}

SEM image of CNTFAS-1 sample (functionalized CNT) is depicted in Figure 7a, revealing the typical wire morphology of MWCNT. In Figure 7b, it can be observed the existence of polyhedral particles of $\mathrm{ZnO}$, as well as CNT wires, for CNT-ZnO-2 sample (having 9.1\% functionalized CNT). CNT wires are better displayed in Figure 7c,d, due to a higher content of carbon nanotubes in $\mathrm{ZnO}-\mathrm{CNT}$ nanocomposite powders $(16.7 \%$ and $20 \%$, respectively). In the case of CNT-ZnO-3 sample (Figure 7c) it can be observed that CNT wires are bounded with $\mathrm{ZnO}$ particles. It can be seen also large $\mathrm{ZnO}$ aggregates having their surface coated with CNT wires (Figure 7d). This is consistent with the results of the thermal analysis, suggesting an excess of CNT (in the case of the CNT-ZnO-4 sample), arranged over the entire $\mathrm{ZnO}$ surface.

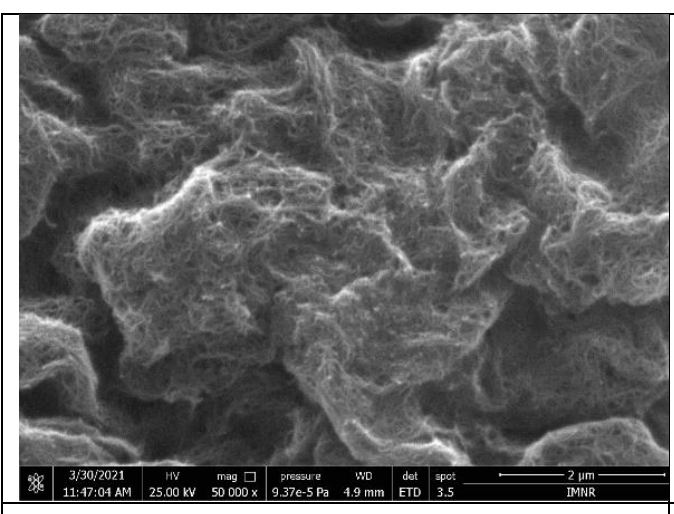

(a)

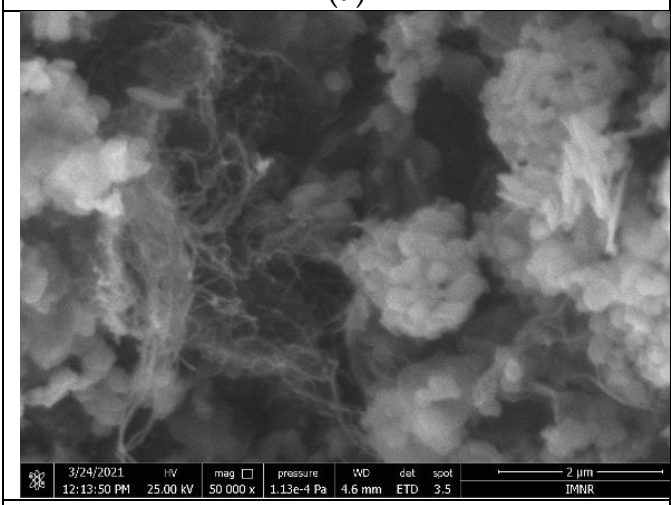

(c)

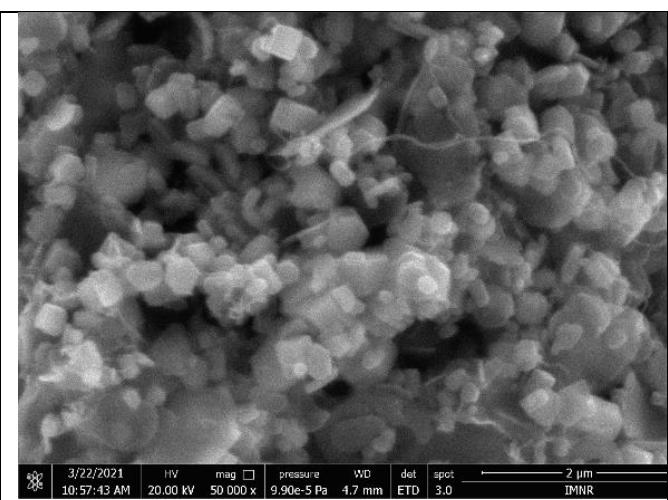

(b)

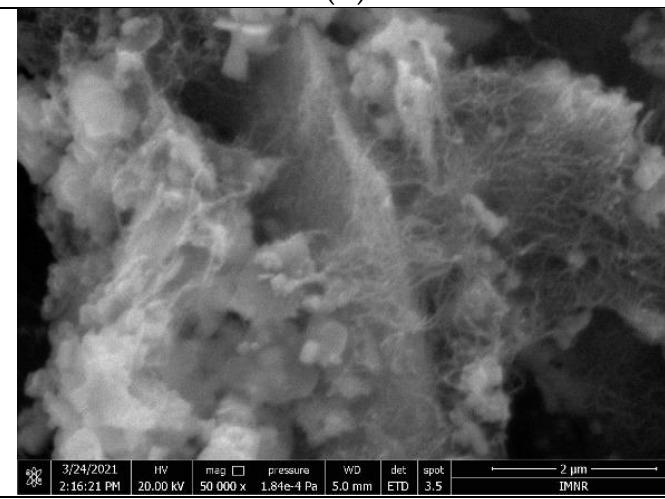

(d)

Figure 7. SEM image of: (a) CNTFAS - 1 sample, $2 \mu \mathrm{m}$ scale, 50,000 $\times$ magnification; (b) CNT-ZnO-2 sample, $2 \mu \mathrm{m}$ scale, 50,000 $\times$ magnification; (c) CNT-ZnO-3 sample, $2 \mu \mathrm{m}$ scale, 50,000 $\times$ magnification; (d) CNT-ZnO-4 sample, $2 \mu \mathrm{m}$ scale, 50,000 $\times$ magnification.

Characterization of nanocomposite samples by energy dispersive $\mathrm{X}$-ray spectroscopy (EDS) showed the presence of $\mathrm{C}, \mathrm{O}, \mathrm{Zn}$, and $\mathrm{S}$.

Based on the morphological characteristics of $\mathrm{ZnO}-\mathrm{CNT}$ nanocomposite powders, it can be concluded that sample CNT-ZnO-2 has a uniform aspect which recommends it for further testing in the preparation of pastes for extrusion-based 3D printing, knowing that particles with a uniform distribution, not agglomerated are suitable for extrusion processing.

3.5. Transmission Electron Microscopy (TEM) Characterization of ZnO-CNT Nanocomposite Powder

TEM images of CNT-ZnO-2 nanocomposite powder are shown in Figure 8a-e. 


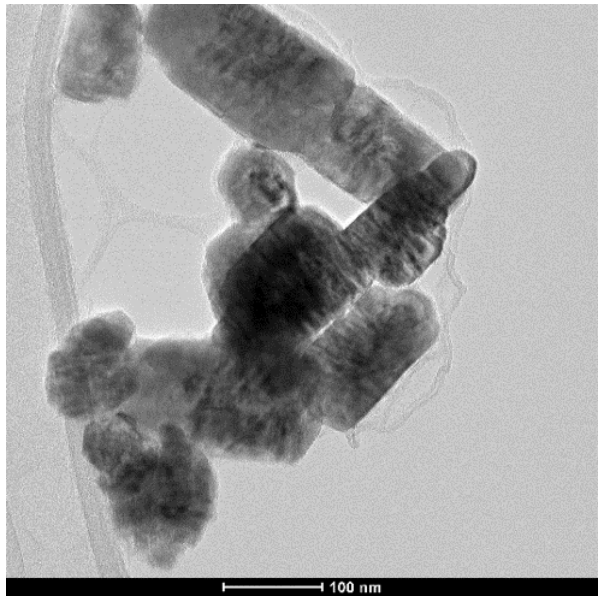

(a)

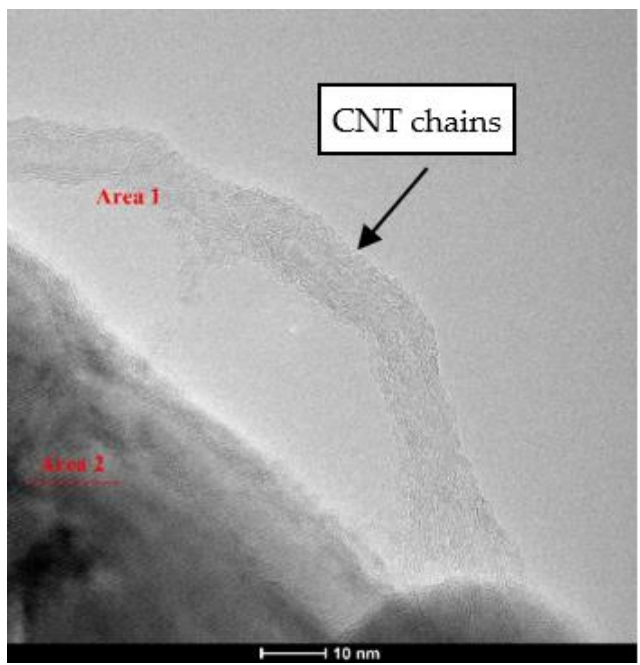

(c)

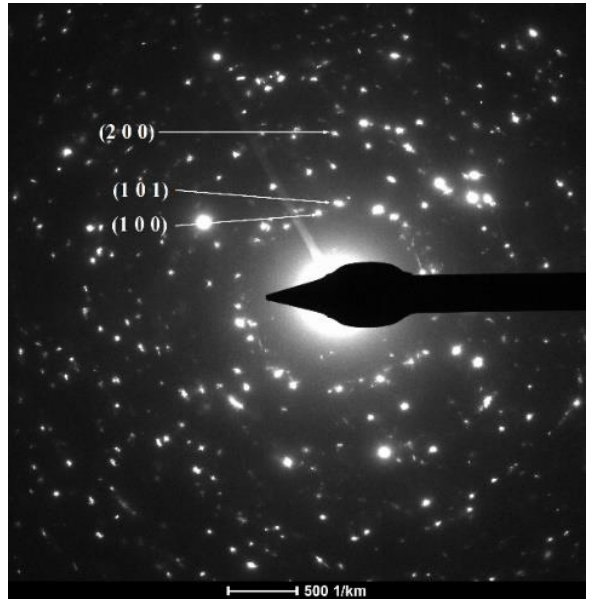

(b)

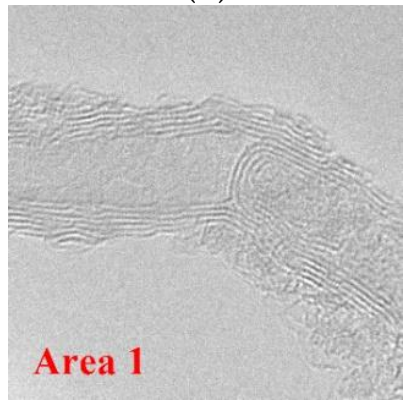

(d)

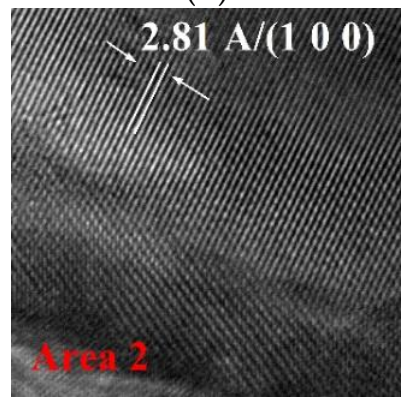

(e)

Figure 8. TEM images of CNT-ZnO-2 (weight ratio CNT:ZnO = 1:10) —nanocomposite sample: (a) polyhedreral rod-like shaped $\mathrm{ZnO}$ nanoparticles covered with CNT (scale $100 \mathrm{~nm}$ ); (b) SAED obtained on ZnO nanoparticles covered on the surface with CNT; (c) HR-TEM image of nanocomposite powder at $10 \mathrm{~nm}$; (d) detail of MWCNT presented in (c,e) detail of crystalline ZnO presented in (c).

It can be observed thin chains of carbon nanotube on the surface of $\mathrm{ZnO}$ particles (Figure 8a,c). Polyhedral rod-like shaped $\mathrm{ZnO}$ nanoparticles have an estimated width between 24 and $80 \mathrm{~nm}$ and an approximate length around $39-160 \mathrm{~nm}$. TEM results confirm our hypothesis regarding the existence of some interactions between $\mathrm{ZnO}$ and $\mathrm{CNT}$ and the formation of nanocomposites with a possible structure presented in Figure 2. Figure 8c shows CNT chains attached on the surface of $\mathrm{ZnO}$ nanoparticles through carboxylic groups of CNTs. During hydrothermal synthesis, this process of forming the physical bonds between the carboxylic groups of $\mathrm{CNT}$ and $\mathrm{ZnO}$ nanoparticles is favored by pressure. The carboxylic groups on the MWCNTs surface act as reaction sites in the hydrothermal process [9], leading to the formation of Zn-O-OOC-MWCNT structure presented in Equation (2), simultaneously with $\mathrm{ZnO}$ crystallization. From SAED Image presented in Figure 8 b, we can identify only hexagonal $\mathrm{ZnO}$. Insets presented in Figure 8d,e clearly shows the formation of MWCNT (Figure 8d) and highly crystalline $\mathrm{ZnO}$ nanoparticles, on which we can identify the 100 orientations of the Miller indices of $2.81 \AA$. 
Figure 9 shows TEM images of samples CNT-ZnO-3 (weight ratio CNT:ZnO = 1:5) and CNT-ZNO-4 (weight ratio CNT:ZnO = 1:4). In the case of CNT-ZnO-3 nanopowder, it can be observed a ZnO particle covered by CNT chains (Figure 9a,b). However, when the percent of CNT increases in nanocomposite samples (CNT-ZnO-4), ZnO nanoparticles are entrapped in CNT mass. A high degree of agglomeration for CNT chains is observed. In the same time, $\mathrm{CNT}$ are attached on the surface of $\mathrm{ZnO}$ through carboxylic groups for all nanocomposite samples. As concluded also from thermal analysis (DSC-TG) and SEM characterization, it could be said that sample CNT-ZnO-2 $(\mathrm{CNT}: \mathrm{ZnO}$ weight ratio $=1: 10)$ is the most suitable from the point of view of physical interactions between the two components of nanocomposite, thermal behavior and morphological characteristics.

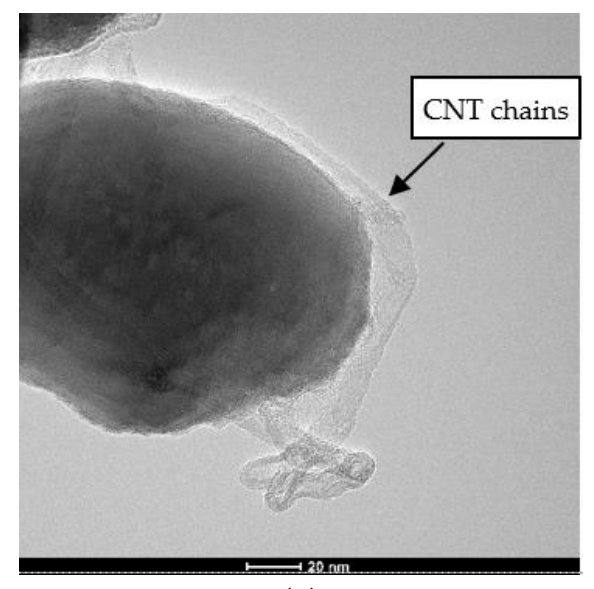

(a)

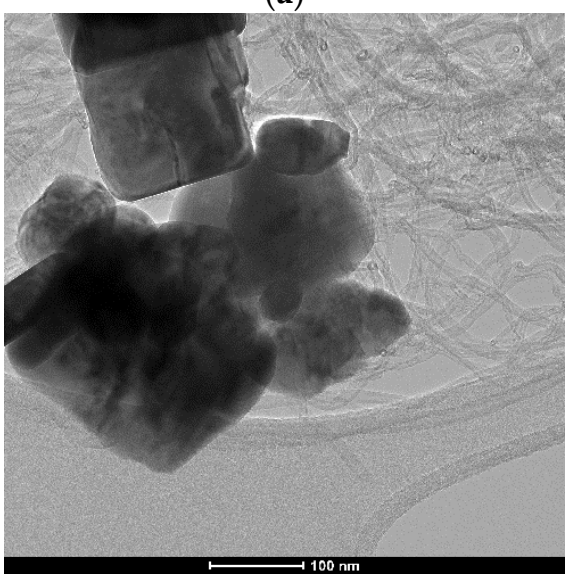

(c)

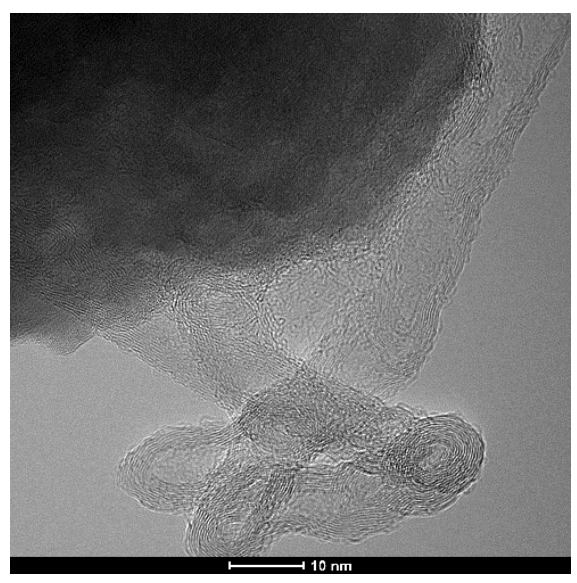

(b)

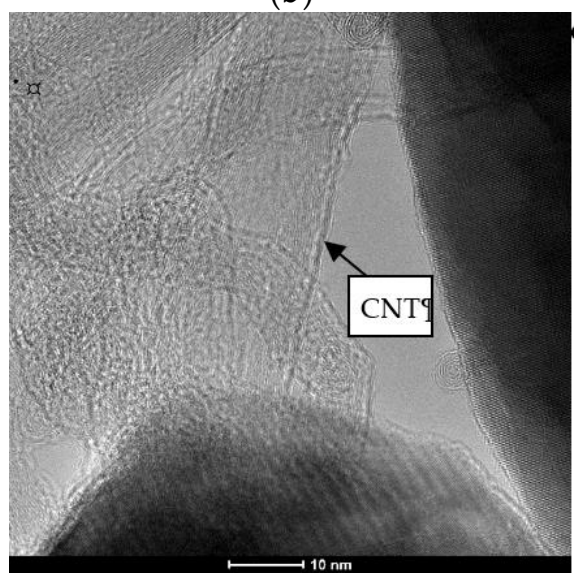

(d)

Figure 9. TEM images of CNT-ZnO-3 (weight ratio $\mathrm{CNT}: \mathrm{ZnO}=1: 5$ ) and $\mathrm{CNT}-\mathrm{ZnO}-4$ (weight ratio $\mathrm{CNT}: \mathrm{ZnO}=1: 4$ ) nanocomposite powders: (a) CNT-ZnO-3 sample. Polyhedreral rod-like shaped ZnO nanoparticles covered with CNT (scale $20 \mathrm{~nm}$ ); (b) HR-TEM image of CNT-ZnO-3 nanocomposite powder at $10 \mathrm{~nm}$; (c) CNT-ZnO-4 sample. Polyhedreral rod-like shaped $\mathrm{ZnO}$ nanoparticles covered with CNT (scale $100 \mathrm{~nm}$ ); (d) HR-TEM image of CNT-ZnO-4 nanocomposite powder at $10 \mathrm{~nm}$.

\subsection{XRD Characterization of ZnO-CNT Nanocomposites}

$\mathrm{X}$-ray diffraction spectra of ZnO-CNT nanocomposite samples are presented in Figure 10. Figure 10 presents the overlapped XRD patterns of the obtained samples. The XRD analysis revealed the presence of a major phase with hexagonal structure, which can be attributed to $\mathrm{ZnO}$ (ICDD PDF no. 01-070-8070). Moreover, the analysis reveals the existence of other minor phases, probably due to zinc sulphate appeared as a secondary product during CNT functionalization. Thus, a crystalline phase with a hexagonal symmetry (space group P3 (143), Pearson symbol hP46), (ICDD PDF no. 00-045-1386) is observed in all nanocomposite samples. C (from carbon nanotubes chains, (ICDD PDF no. 01-074-2328)) 
and $\mathrm{NaNO}_{3}$ (as the secondary reaction product of hydrothermal synthesis, according to equation 1, ICDD PDF no. 04-007-2328) structures could be detected in the case of CNT-ZnO-3 (CNT:ZnO = 1:5 mass ratio) and CNT-ZnO-4 samples (CNT:ZnO = 1:4 mass ratio). The presence of $C$ (from CNT chains) in the XRD spectra of CNT-ZnO-3 and CNT$\mathrm{ZnO}-4$ samples demonstrates the excess amount of CNT in the nanocomposite samples, in accordance with the observations from thermal analysis results.

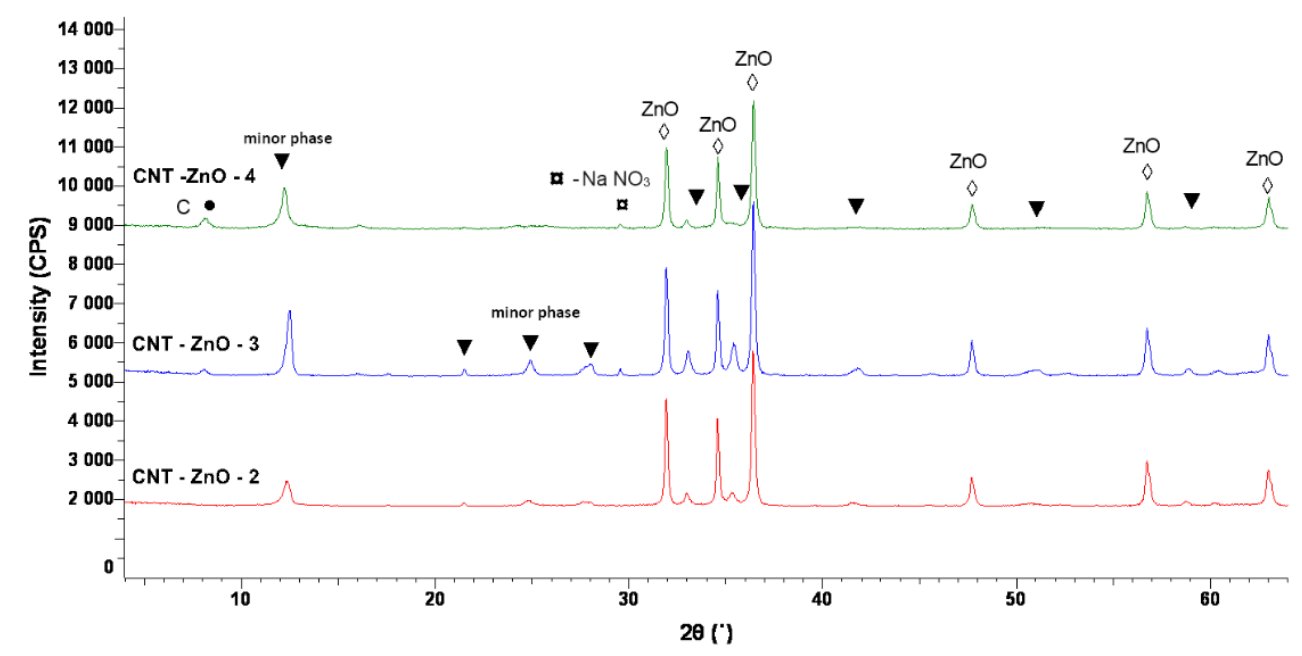

Figure 10. XRD spectra of CNT-ZnO-2 (1:10)—red; CNT-ZnO-3 (1:5)—blue, and CNT-ZnO-4 (1:4)— green nanocomposite samples.

The crystallite size calculated in (101) direction, using Scherrer equation [6] (Equation (3)) is $61 \mathrm{~nm}$ in the case of CNT-ZnO-2 sample (CNT:ZnO $=1: 10$ mass ratio), around $\sim 60 \mathrm{~nm}$ for CNT-ZnO-3 sample (CNT:ZnO = 1:5 mass ratio), and $54 \mathrm{~nm}$ in the case of CNT-ZnO-4 sample (CNT:ZnO = 1:5 mass ratio), decreasing slightly with the increase of CNT content.

$$
D=\frac{\kappa \lambda}{\beta \cos \theta}
$$

where:

$D$ —the average crystallite size, in $\mathrm{nm}$

$\beta$-the line broadening at half the maximum intensity, in radians,

$\lambda$ 一the X-ray wavelength, in $\AA$;

$\kappa=$ constant; $\kappa=0.9$ according to Bragg or $0.70<\kappa<1.70$ according to Klug and Alexander $\theta$-diffraction (Bragg) angle.

\subsection{Extrusion-Based 3D Printing of $\mathrm{ZnO}-\mathrm{CNT}$ Nanocomposite Powders}

Based on the results obtained at characterization of nanocomposite powder, sample ZnO-CNT-2 having CNT:ZnO = 1:10 mass ratio has been chosen as a potential candidate to be processed in the form of pastes for preliminary experiments concerning fabrication of ZnO-CNT 3D structures by extrusion-based 3D printing.

In order to obtain the 3D structures from the $\mathrm{ZnO}-\mathrm{CNT}$ nanocomposite powders several polymeric additives (binders, extrusion agents, viscosity agents) were tested: Mowiflex (crosslinked polyvinyl alcohol), Baymedix (aqueous polyurethane dispersion), poly (acrylic acid sodium salt) (PAAS), polyethyleneimine (PEI), ethylene glycol (EG), hydroxypropylmethylcellulose (HPMC), Tween 80 (polysorbate 80), Triton X-100 (polyoxyethylene octyl phenyl ether), and polylactic acid (PLA). The compositions of the prepared pastes are shown in Table 5. The additive type or the amount used significantly affects the printability and homogeneity of the obtained pastes. A homogeneous and printable paste was obtained by adding a combination of HPMC, PEI, and Tween 80 additives. The optimum composition that leads to a printable paste and to the tridimensional structure shown in 
Figure 11 was: $45.1 \%$ CNT-ZnO-2 nanopowder, 26.9\% HPMC, 3.4\% Tween 80, and 24.6\% PEI. This composition corresponds to the structure 3D-9 in Table 5.

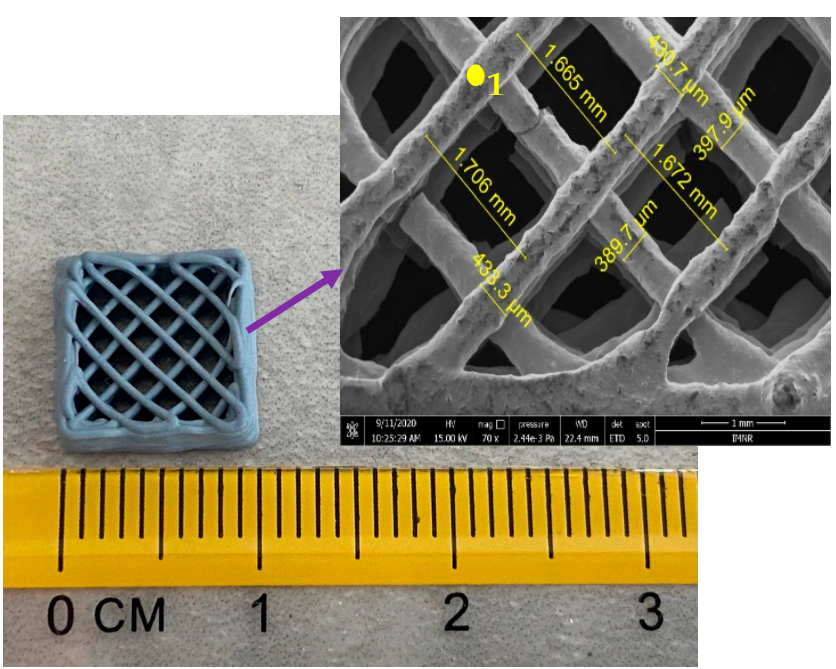

Figure 11. An example of CNT-ZnO 3D printed structure (3D-9 sample) at normal scale and microscopic scale.

Table 5. The composition of printable pastes used for the manufacture of 3D structures from CNT-ZnO-2 nanopowders.

\begin{tabular}{|c|c|c|c|c|}
\hline No. & 3D Object Name & Polymeric Additives & Printing Parameters & Observations \\
\hline 1 & 3D-1 & $\begin{array}{l}\text { Mowiflex 20\% } \\
\text { BAYMEDIX }\end{array}$ & - & Non-homogeneous paste. Non-printable paste. \\
\hline 2 & 3D-2 & $\begin{array}{l}\text { HPMC } \\
\text { PAAS }\end{array}$ & - & $\begin{array}{l}\text { The paste could not be extruded through } \\
\text { the nozzle. } \\
\text { Non-printable paste. }\end{array}$ \\
\hline 3 & $3 \mathrm{D}-3$ & $\begin{array}{l}\text { HPMC } \\
\text { PAAS }\end{array}$ & $\begin{array}{c}\mathrm{P}=5 \mathrm{bar} \\
\mathrm{v}=3.5 \mathrm{~mm} / \mathrm{s} \\
\text { nozzle } \varphi=0.4 \mathrm{~mm}\end{array}$ & $\begin{array}{l}\text { The paste is extruded in dots. The wire is not } \\
\text { continuous. Non-printable paste. }\end{array}$ \\
\hline 4 & $3 \mathrm{D}-4$ & $\begin{array}{l}\text { Tween } 80 \\
\text { HPMC } \\
\text { ethylene glycol }\end{array}$ & - & $\begin{array}{l}\text { The paste is not homogeneous and is partially } \\
\text { extrudable. Non-printable paste. }\end{array}$ \\
\hline 5 & $3 \mathrm{D}-5$ & $\begin{array}{l}\text { HPMC } \\
\text { PEI }\end{array}$ & $\begin{array}{c}\mathrm{P}=3.5 \mathrm{bar} \\
\mathrm{v}=10 \mathrm{~mm} / \mathrm{s} \\
\text { nozzle } \varphi=0.4 \mathrm{~mm}\end{array}$ & Printable paste, a 3D object was obtained. \\
\hline 6 & $3 \mathrm{D}-6$ & $\begin{array}{l}\text { HPMC } \\
\text { PEI } \\
\text { Tween } 80\end{array}$ & $\begin{array}{c}\mathrm{P}=3.5 \mathrm{bar} \\
\mathrm{v}=10 \mathrm{~mm} / \mathrm{s} \\
\text { nozzle } \varphi=0.4 \mathrm{~mm}\end{array}$ & Printable paste, a 3D object was obtained. \\
\hline 7 & 3D-7 & $\begin{array}{l}\text { HPMC } \\
\text { PEI } \\
\text { Tween } 80\end{array}$ & $\begin{array}{c}\mathrm{P}=3.5 \mathrm{bar} \\
\mathrm{v}=10 \mathrm{~mm} / \mathrm{s} \\
\text { nozzle } \varphi=0.4 \mathrm{~mm}\end{array}$ & Printable paste, a 3D object was obtained. \\
\hline 8 & $3 \mathrm{D}-8$ & $\begin{array}{c}\text { HPMC } \\
\text { PEI } \\
\text { Tween } 80\end{array}$ & $\begin{array}{c}\mathrm{P}=2 \mathrm{bar} \\
\mathrm{v}=15 \mathrm{~mm} / \mathrm{s} \\
\text { nozzle } \varphi=0.4 \mathrm{~mm}\end{array}$ & Printable paste, a 3D object was obtained. \\
\hline 9 & 3D-9 & $\begin{array}{c}\text { PEI } \\
\text { HPMC } \\
\text { Tween } 80\end{array}$ & $\begin{array}{c}\mathrm{P}=2 \mathrm{bar} \\
\mathrm{v}=15 \mathrm{~mm} / \mathrm{s} \\
\text { nozzle } \varphi=0.4 \mathrm{~mm}\end{array}$ & Printable paste, a 3D object was obtained. \\
\hline
\end{tabular}


Table 5. Cont.

\begin{tabular}{ccccc}
\hline No. & 3D Object Name & Polymeric Additives & Printing Parameters & Observations \\
\hline 10 & 3D-10 & $\begin{array}{c}\text { PEI } \\
\text { HPMC } \\
\text { Tween } 80\end{array}$ & $\begin{array}{c}\mathrm{P}=1.5-2 \mathrm{bar}, \\
\mathrm{v}=12-16 \mathrm{~mm} / \mathrm{s} \\
\text { nozzle } \varphi=0.4 \mathrm{~mm}\end{array}$ & $\begin{array}{c}\text { Printable paste, a 3D object was obtained. } \\
\text { 11 }\end{array}$ \\
\hline 3D-11 & $\begin{array}{c}\text { PEI } \\
\text { Tween } 80\end{array}$ & $\begin{array}{c}\mathrm{P}=4.5 \mathrm{bar}, \\
\mathrm{v}=7 \mathrm{~mm} / \mathrm{s}\end{array}$ & Printable paste, a 3D object was obtained. \\
\hline 12 & 3D-12 & $\begin{array}{c}\mathrm{P}=0.4 \mathrm{~mm} \\
\mathrm{P}=6 \mathrm{~mm} / \mathrm{s}\end{array}$ & Printable paste, a 3D object was obtained. \\
\hline
\end{tabular}

The 3D-9 sample is presented in Figure 11, emphasizing the dimensions of the 3D structure both on a normal scale and on a microscopic scale.

SEM image of 3D-9 sample is depicted in Figure 12a. The strand thickness varies between 397.9 and $433.3 \mu \mathrm{m}$, in accordance with the nozzle diameter of $400 \mu \mathrm{m}$. The distance between fibers varies between 1.665 and $1.706 \mathrm{~mm}$, in accordance with the selected distance of $2 \mathrm{~mm}$. Results of the EDS analysis of the 3D-9 sample performed in spot 1 shown in Figure 12a are presented in Figure 12b. The existence of C, O, and $\mathrm{Zn}$ can be observed.

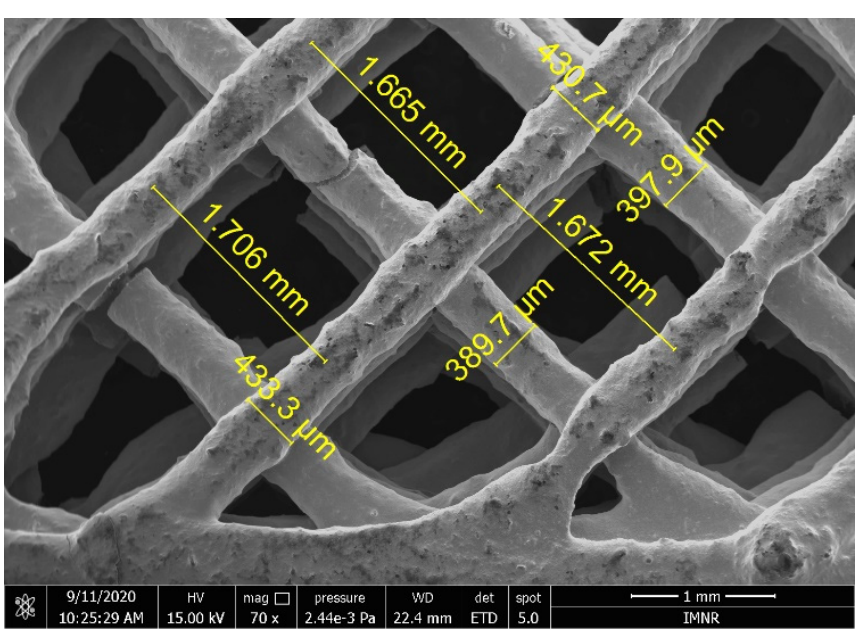

(a)

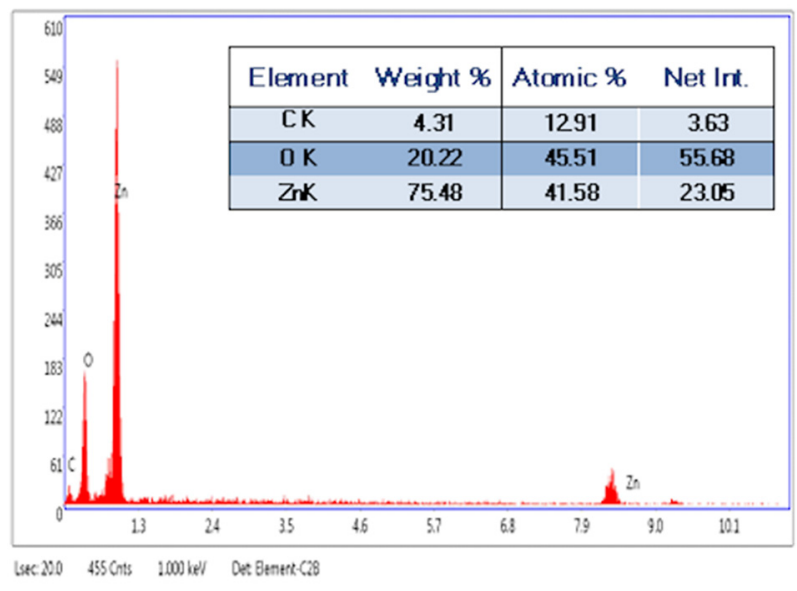

(b)

Figure 12. (a) SEM micrograph of 3D-9 sample; (b) EDS spectrum of 3D-9 sample.

\section{Conclusions}

Different types of ZnO-CNT-based nanocomposite powders were obtained by hydrothermal process in high-pressure conditions, aiming to investigate the potential of CNT-ZnO nanocomposite powders to be processed in the form of pastes for 3D printing by extrusion. The formation of functionalized CNT-ZnO-nanocomposites has been demonstrated by spectral, thermal, and morpho-structural investigations. Thus, FT-IR spectra suggest the existence of some interactions between carboxylic groups of functionalized $\mathrm{CNT}$ and $\mathrm{ZnO}$, by shifting or masking specific vibration bands of functionalized CNT. The presence of $\mathrm{ZnO}$ is confirmed by the specific vibration band of metal-oxygen bonds at $592 \mathrm{~cm}^{-1}$. DSC-TG thermal analysis confirms the formation of physical bonds between functionalized $\mathrm{CNT}$ and $\mathrm{ZnO}$, by the appearance of some endothermic peaks in the range 196-233 ${ }^{\circ} \mathrm{C}$, which could be due to the breaking of these CNT-ZnO bonds. TEM results clearly showed thin chains of CNT on the $\mathrm{ZnO}$ surface and the interaction between them, confirming the formation of nanocomposites with physical bonds in the case of CNT-ZnO-2 sample $(\mathrm{CNT}: \mathrm{ZnO}$ mass ratio $=1: 10)$. 
Correlation of DSC-TG and XRD results suggested that an excess amount of CNT, which is not bonded with $\mathrm{ZnO}$ is present in CNT-ZnO-3 (CNT:ZnO mass ratio $=1: 5)$ and CNT-ZnO-4 (CNT:ZnO mass ratio = 1:4) samples. Further studies for the fabrication of ZnO-CNT 3D structures are based on nanocomposite powders having CNT:ZnO mass ratio $=1: 10$ (CNT-ZnO-2 nanocomposite powder), which has been chosen as the most appropriate for the preparation of printable pastes. An example of CNT-ZnO 3D structure fabricated by extrusion-based 3D printing process, starting from hydrothermally synthesized nanocomposites and polymeric binders has been shown. Further work is under development to find some possible applications of $\mathrm{ZnO}-\mathrm{CNT} 3 \mathrm{D}$ nanocomposite structures.

Author Contributions: Conceptualization L.-M.C. and R.M.P.; methodology, L.-M.C.; investigation, S.N.V., M.-E.P., I.A.T., N.Z.-I. and B.S.V.; writing-original draft preparation, L.-M.C. and M.-E.P.; writing-review and editing, L.-M.C., B.S.V. and R.M.P.; supervision, R.M.P.; project administration, L.-M.C. All authors have read and agreed to the published version of the manuscript.

Funding: This research was funded by Core Program; grant number PN19190101/2019 and ERANETMANUNET-NYMPH project, ctr. no 208/2020.

Institutional Review Board Statement: Not applicable.

Informed Consent Statement: Not applicable.

Data Availability Statement: The data presented in this study are available on request from the corresponding author.

Acknowledgments: We thank Dumitru Valentin Dragut for X-ray diffraction measurements.

Conflicts of Interest: The authors declare no conflict of interest.

\section{References}

1. Ba-abbad, M.M.; Amir, A.; Kadhum, H.; Bakar, A.; Takriff, M.S. Visible light photocatalytic activity of Fe ${ }^{3+}$ doped $_{\text {ZnO nanoparticle }}$ prepared via sol-gel technique. Chemosphere 2013, 91, 1604-1611. [CrossRef] [PubMed]

2. Zhong, J.; Li, J.; He, X.; Zeng, J.; Lu, Y.; Hu, W.; Lin, K. Improved photocatalytic performance of Pd-doped ZnO. Curr. Appl. Phys. 2012, 12, 998-1001. [CrossRef]

3. Rabin, N.N.; Morshed, J.; Akhter, H.; Islam, M.S.; Hossain, M.A.; Elias, M.; Alam, M.M.; Karim, M.R.; Hasnat, M.A.; Nizam uddin, M.; et al. Surface modification of the $\mathrm{ZnO}$ nanoparticles with g-aminopropyltriethoxysilane and study of their photocatalytic activity, optical properties and antibacterial activities. Int. J. Chem. React. Eng. 2016, 14, 785-794. [CrossRef]

4. Sakthivel, S.; Neppolian, B.; Shankar, M.V.; Arabindoo, B.; Palanichamy, M.; Murugesan, V. Solar photocatalytic degradation of azo dye: Comparison of photocatalytic efficiency of $\mathrm{ZnO}$ and $\mathrm{TiO}_{2}$. Sol. Energy Mater. Sol. Cells 2003, 77, 65-82. [CrossRef]

5. Jongnavakit, P.; Amornpitoksuk, P.; Suwanboon, S.; Ndiege, N. Preparation and photocatalytic activity of Cu-doped ZnO thin films prepared by the sol-gel method. Appl. Surf. Sci. 2012, 258, 8192-8198. [CrossRef]

6. Elias, M.; Nizam Uddin, M.; Hossain, M.A.; Saha, J.K.; Siddiquey, I.A.; Sarker, D.R.; Diba, Z.R.; Uddin, J.; Choudhury, M.H.R.; Firoz, S.H. An experimental and theoretical study of the effect of Ce doping in ZnO/CNT composite thin film with enhanced visible light photo-catalysis. Int. J. Hydrogen Energy 2019, 44, 20068-20078. [CrossRef]

7. Gouvea, C.A.K.; Wypych, F.; Moraes, S.G.; Duran, N.; Nagata, N.; Peralta-Zamora, P. Semiconductor-assisted photocatalytic degradation of reactive dyes in aqueous solution. Chemosphere 2000, 40, 433-440. [CrossRef]

8. Ren, X.L.; Han, D.; Chen, D.; Tang, F.Q. Large-scale synthesis of hexagonal cone-shaped ZnO nanoparticles with a simple route and their application to photocatalytic degradation. Mater. Res. Bull. 2007, 42, 807-813. [CrossRef]

9. Yan, Y.; Chang, T.; Wei, P.; Kang, S.-Z.; Mu, J. Photocatalytic Activity of Nanocomposites of ZnO and Multi-Walled Carbon Nanotubes for Dye Degradation. J. Dispers. Sci. Technol. 2009, 30, 198-203. [CrossRef]

10. Height, M.J.; Pratsinis, S.E.; Mekasuwandumrong, O.; Praserthdam, P. Ag-ZnO catalysts for UV-photodegradation of methylene blue. Appl. Catal. B 2006, 63, 305-312. [CrossRef]

11. Matthews, R.W. Photooxidative degradation of coloured organics in water using supported catalysts $\mathrm{TiO}_{2}$ on sand. Water Res. 1991, 25, 1169-1176. [CrossRef]

12. Li, S.; Zhang, M.; Gao, Y.; Bao, B.; Wang, S. ZnO-Zn/CNT hybrid film as light-free nanocatalyst for degradation reaction. Nano Energy 2013, 2, 1329-1336. [CrossRef]

13. Chen, C.C.; Liu, P.; Lu, C.H. Synthesis and characterization of nano sized ZnO powders by direct precipitation method. Chem. Eng. J. 2008, 144, 509-513. [CrossRef]

14. Samadi, M.; Zirak, M.; Naseri, A.; Kheirabadi, M.; Ebrahimi, M.; Moshfegh, A.Z. Design and tailoring of one-dimensional ZnO nanomaterials for photocatalytic degradation of organic dyes: A review. Res. Chem. Intermed. 2019, 45, 2197-2254. [CrossRef] 
15. Hilding, J.; Grulke, E.A.; Sinnott, S.B.; Qian, D.L.; Andrews, R.; Jagtoyen, M. Sorption of butane on carbon multiwall nanotubes at room temperature. Langmuir 2001, 17, 7540-7544. [CrossRef]

16. Wang, X.; Chen, C.; Hu, W.; Ding, A.; Xu, D.; Zhou, X. Sorption of 243Am (III) to multiwall carbon nanotubes. Environ. Sci. Technol. 2005, 39, 2856-2860. [CrossRef] [PubMed]

17. Lu, H.; Wang, J.; Stoller, M.; Wang, T.; Bao, Y.; Hao, H. An Overview of Nanomaterials for Water and Wastewater Treatment. Adv. Mater. Sci. 2016, 2016, 4964828. [CrossRef]

18. Abdelbasir, S.M.; Shalan, A.E. An overview of nanomaterials for industrial wastewater treatment. Korean J. Chem. Eng. 2019, 36, 1209-1225. [CrossRef]

19. Aravinda, L.S.; Nagaraja, K.K.; Nagaraja, H.S.; Bhat, K.U.; Bhat, B.R. ZnO/carbon nanotube nanocomposite for high energy density supercapacitors. Electrochim. Acta 2013, 95, 119-124. [CrossRef]

20. Anku, W.W.; Agorku, E.S.; Oppong, S.O.B.; Karikari, A.Y. MWCNTs attached neodymium doped-ZnO photocatalysts for efficient removal of dyes from wastewater. SN Appl. Sci. 2020, 2, 1-13. [CrossRef]

21. Mazloumi, M.; Shadmehr, S.; Rangom, Y.; Nazar, L.F.; Tang, X. Fabrication of three-dimensional carbon nanotube and metal oxide hybrid mesoporous architectures. ACS Nano 2013, 7, 4281-4288. [CrossRef]

22. Azqhandi, M.H.A.; Vasheghani, B.F.; Rajabi, F.H.; Keramati, M. Synthesis of Cd doped ZnO/CNT nanocomposite by using microwave method: Photocatalytic behavior, adsorption and kinetic study. Res. Phys. 2017, 7, 1106-1114. [CrossRef]

23. Elahi, A.S.; Agah, K.M.; Ghoranneviss, M. A new perspective on structural and morphological properties of carbon nanotubes synthesized by Plasma Enhanced Chemical Vapor Deposition technique. Res. Phys. 2017, 7, 757-761.

24. Elashmawi, I.S.; Gaabour, L.H. Raman, morphology and electrical behavior of nanocomposites based on PEO/PVDF with multi-walled carbon nanotubes. Res. Phys. 2015, 5, 105-110. [CrossRef]

25. Nezhadheydari, H.; Tavabe, K.R.; Mirvaghefi, A.; Heydari, A.; Frinsko, M. Effects of different concentrations of Fe $\mathrm{O}_{4}-\mathrm{ZnO}_{\mathrm{n}}$ and $\mathrm{Fe}_{3} \mathrm{O}_{4}$-CNT. Environ. Technol. Innov. 2019, 15, 100414. [CrossRef]

26. Khin, M.M.; Nair, A.S.; Babu, V.J.; Murugan, R.; Ramakrishna, S. A review on nanomaterials for environmental remediation. Energy Environ. Sci. 2012, 5, 8075-8109. [CrossRef]

27. Anjum, M.; Miandad, R.; Waqas, M.; Gehany, F.; Barakat, M.A. Remediation of wastewater using various nano-materials. Arab. J. Chem. 2016, 12, 4897-4919. [CrossRef]

28. Abdulgafour, H.I.; Alkhayat, Z.Q.; Nazal, Z.F. The temperatures effects on treatment of heavy metals with zinc oxide nano tubes from industrial wastewater. IOP Conf. Ser. Mater. Sci. Eng. 2018, 400, 7. [CrossRef]

29. Arora, B.; Attri, P. Carbon Nanotubes (CNTs): A Potential Nanomaterial for Water Purification. J. Compos. Sci. 2020, 4, 135. [CrossRef]

30. Mohd Adnan, M.A.; Julkapli, N.M.; Abd Hamid, S.B. Review on ZnO hybrid photocatalyst: Impact on photocatalytic activities of water pollutant degradation. Rev. Inorg. Chem. 2016, 36, 77-104. [CrossRef]

31. Saleh, T.A.; Gondal, M.A.; Drmosh, Q.A. Preparation of a MWCNT/ZnO nanocomposite and its photocatalytic activity for the removal of cyanide from water using a laser. Nanotechnology 2010, 21, 495705. [CrossRef] [PubMed]

32. Oliveira, I.E.; Silva, R.M.; Girão, A.V.; Faria, J.L.; Silva, C.G.; Silva, R.F. Facile Preparation of ZnO/CNTs Nanocomposites via ALD for Photocatalysis Applications. Eur. J. Inorg. Chem. 2020, 2020, 1743-1750. [CrossRef]

33. Byrappa, K.; Dayananda, A.S.; Sajan, C.P.; Basavalingu, B.; Shayan, M.B.; Soga, K.; Yoshimura, M. Hydrothermal preparation of $\mathrm{ZnO}: \mathrm{CNT}$ and $\mathrm{TiO}_{2}: \mathrm{CNT}$ composites and their photocatalytic applications. J. Mater. Sci. 2008, 43, 2348-2355. [CrossRef]

34. Sankapal, B.R.; Gajare, H.B.; Karade, S.S.; Salunkhe, R.R.; Dubal, D.P. Zinc Oxide Encapsulated Carbon Nanotube Thin Films for Energy Storage Applications. Electrochim. Acta 2016, 192, 377-384. [CrossRef]

35. Saleh, T.A.; Gondal, M.; Drmosh, Q.; Yamani, Z.; Al-Yamani, A. Enhancement in photocatalytic activity for acetaldehyde removal by embedding $\mathrm{ZnO}$ nanoparticles on multiwall carbon nanotubes. Chem. Eng. J. 2011, 166, 407-412. [CrossRef]

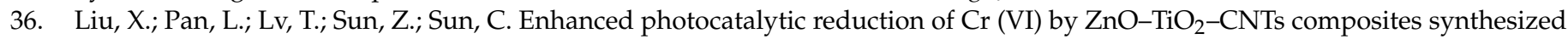
via microwave-assisted reaction. J. Mol. Catal. A Chem. 2012, 363, 417-422. [CrossRef]

37. Wang, C.Y.; Adhikari, S. ZnO-CNT composite nanotubes as nanoresonators. Phys. Lett. A 2011, 375, 2171-2175. [CrossRef]

38. Gupta, V.K.; Norouzi, P.; Ganjali, H.; Faridbod, F.; Ganjali, M.R. Flow injection analysis of cholesterol using FFT admittance voltammetric biosensor based on MWCNT-ZnO nanoparticles. Electrochim. Acta 2013, 100, 29-34. [CrossRef]

39. Hu, F.; Chen, S.; Wang, C.; Yuan, R.; Chai, Y.; Xiang, Y.; Wang, C. ZnO nanoparticle and multiwalled carbon nanotubes for glucose oxidase direct electron transfer and electrocatalytic activity investigation. J. Mol. Catal. B Enzym. 2011, 72, 298. [CrossRef]

40. Palanisamy, S.; Cheemalapati, S.; Chen, S.M. Highly sensitive and selective hydrogen peroxide biosensor based on hemoglobin immobilized at multiwalled carbon nanotubes-zinc oxide composite electrode. Anal. Biochem. 2012, 429, 108. [CrossRef]

41. Zhang, W.; Yang, T.; Huang, D.; Jiao, K.; Li, G. Synergistic effects of nano-ZnO/multi-walled carbon nanotubes/chitosan nanocomposite membrane for the sensitive detection of sequence-specific of PAT gene and PCR amplification of NOS gene. J. Membr. Sci. 2008, 325, 245. [CrossRef]

42. Tak, M.; Gupta, V.; Tomar, M. Zinc oxide-multiwalled carbon nanotubes hybrid nanocomposite-based urea biosensor. J. Mater. Chem. B 2013, 1, 6392-6401. [CrossRef]

43. Zhang, Y.; Sun, X.; Pan, L.; Li, H.; Sun, Z.; Sun, C.; Tay, B.K. Carbon nanotube-ZnO nanocomposite electrodes for supercapacitors. Solid State Ion. 2009, 180, 1525. [CrossRef] 
44. Barthwal, S.; Singh, B.; Barthwal, S.; Singh, N.B. ZnO-CNT Nanocomposite Based Gas Sensors-An Overview. Sens. Lett. 2017, 15, 955-969. [CrossRef]

45. Subagio, A.; Darari, A.; Sulton Hakim, I.; Subhan, A. Preparation and Characterization of Carbon Nanotube/Graphite/Zinc Oxide Composite as Supercapacitor Electrode Material. MSF 2018, 929, 121-127. [CrossRef]

46. Suroshe, J.S.; Garje, S.S. Capacitive behaviour of functionalized carbon nanotube/ZnO composites coated on a glassy carbon electrode. J. Mater. Chem. A 2015, 3, 15650-15660. [CrossRef]

47. Zhu, G.; Wang, H.; Yang, G.; Chen, L.; Guo, P.; Zhang, L. A facile synthesis of ZnO/CNT hierarchical microsphere composites with enhanced photocatalytic degradation of methylene blue. RSC Adv. 2015, 5, 72476-72481. [CrossRef]

48. Dai, K.; Dawson, G.; Yang, S.; Chen, Z.; Lu, L. Large scale preparing carbon nanotube/zinc oxide hybrid and its application for highly reusable photocatalyst. Chem. Eng. J. 2012, 191, 571-578. [CrossRef]

49. Barthwal, S.; Singh, N.B. ZnO-CNT Nanocomposite: A Device as Electrochemical Sensor. Mater. Today-Proc. 2017, 4, 5552-5560. [CrossRef]

50. Pahlavan, A.; Gupta, V.K.; Sanati, A.L.; Karimi, F.; Yoosefian, M.; Ghadami, M. ZnO/CNTs nanocomposite/ionic liquid carbon paste electrode for determination of noradrenaline in human samples. Electrochim. Acta 2014, 123, 456-462. [CrossRef]

51. Wang, D.; Guo, J.; Cui, C.; Ma, J.; Cao, A. Controllable synthesis of CNT@ZnO composites with enhanced electrochemical properties for lithium-ion battery. Mater. Res. Bull. 2018, 101, 305-310. [CrossRef]

52. Afsharmanesh, E.; Karimi-Maleh, H.; Pahlavan, A.; Vahedi, J. Electrochemical behavior of morphine at ZnO/CNT nanocomposite room temperature ionic liquid modified carbon paste electrode and its determination in real samples. J. Mol. Liq. 2013, 181, 8-13. [CrossRef]

53. Ranjithkumar, R.; Arasi, S.E.; Sudhahar, S.; Nallamuthu, N.; Devendran, P.; Lakshmanan, P.; Kumar, M.K. Enhanced electrochemical studies of $\mathrm{ZnO} / \mathrm{CNT}$ nanocomposite for supercapacitor devices. Phys. B Condens. Matter 2019, 568, 51-59. [CrossRef]

54. Sun, Z.; Guo, Y.; Li, B.; Tan, T.; Zhao, Y. ZnO/carbon nanotube/reduced graphene oxide composite film as an effective interlayer for lithium/sulfur batteries. Solid State Sci. 2019, 95, 105924. [CrossRef]

55. Zhang, W. De Growth of ZnO nanowires on modified well-aligned carbon nanotube arrays. Nanotechnology 2006, 17, 1036-1040. [CrossRef]

56. Ramar, A.; Soundappan, T.; Chen, S.-M.; Rajkumar, M.; Ramiah, S. Incorporation of Multi-Walled Carbon Nanotubes in ZnO for Dye Sensitized Solar Cells. Int. J. Electrochem. Sci. 2012, 7, 11734-11744.

57. Gogotsi, Y.; Libera, J.A.; Yoshimura, M. Hydrothermal synthesis of multiwall carbon nanotubes. J. Mater. Res. 2000, 15, 2591-2594. [CrossRef]

58. Yoshimura, M.; Suchanek, W. In situ fabrication of morphology-controlled advanced ceramic materials by Soft Solution Processing. Solid State Ion. 1997, 98, 197-208. [CrossRef]

59. Somiya, S.; Roy, R. Hydrothermal synthesis of fine oxide powders. Bull. Mater. Sci. 2000, 23, 453-460.

60. Ding, M.; Sahebgharani, N.; Musharavati, F.; Jaber, F.; Zalnezhad, E.; Yoon, G.H. Synthesis and properties of HA/ZnO/CNT nanocomposite. Ceram. Int. 2018, 44, 7746-7753.

61. Popescu, L.M.; Piticescu, R.M.; Petriceanu, M.; Ottaviani, M.F.; Cangiotti, M.; Vasile, E.; Dîrtu, M.M.; Wolff, M.; Garcia, Y.; Schinteie, G.; et al. Hydrothermal synthesis of nanostructured hybrids based on iron oxide and branched PEI polymers. Influence of high pressure on structure and morphology. Mater. Chem. Phys. 2015, 161, 84-95. [CrossRef]

62. Demazeau, G. Impact of High Pressures in Solvothermal Processes. J. Phys. Conf. Ser. 2010, 215, 012124. [CrossRef]

63. Ahmed, D.S.; Haider, A.J.; Mohammad, M.R. Comparesion of Functionalization of Multi-Walled Carbon Nanotubes Treated by Oil Olive and Nitric Acid and their Characterization. Energy Procedia 2013, 36, 1111-1118. [CrossRef]

64. Girei, S.A.; Thomas, S.P.; Atieh, M.A.; Mezghani, K.; De, S.K.; Bandyopadhyay, S.; Al-Juhani, A. Effect of -COOH Functionalized Carbon Nanotubes on Mechanical, Dynamic Mechanical and Thermal Properties of Polypropylene Nanocomposites. J. Thermoplast. Compos. Mater. 2011, 25, 333-350. [CrossRef]

65. Jayarambabu, N.; Siva Kumari, B.; Venkateswara Rao, K.; Prabhu, Y.T. Germination and Growth Characteristics of Mungbean Seeds (Vigna radiata L.) affected by Synthesized Zinc Oxide Nanoparticles. Int. J. Curr. Eng. Technol. 2014, 4, $3411-3416$.

66. Liang, S.; Li, G.; Tian, R. Multi-walled carbon nanotubes functionalized with an ultrahigh fraction of carboxyl and hydroxyl groups by ultrasound-assisted oxidation. J. Mater. Sci. 2015, 51, 3513-3524. [CrossRef]

67. Lehman, J.H.; Terrones, M.; Mansfield, E.; Hurst, K.E.; Meunier, V. Evaluating the characteristics of multiwall carbon nanotubes. Carbon 2011, 49, 2581-2602. [CrossRef] 